\title{
Mid-life epigenetic age, neuroimaging brain age, and cognitive function: coronary artery risk development in young adults (CARDIA) study
}

Yinan Zheng ${ }^{1, *}$, Mohamad Habes ${ }^{2,3, *}$, Mitzi Gonzales ${ }^{2}$, Raymond Pomponio ${ }^{3}$, Ilya Nasrallah ${ }^{3}$, Sadiya Khan ${ }^{1,4}$, Douglas E. Vaughan ${ }^{5}$, Christos Davatzikos ${ }^{3}$, Sudha Seshadri' ${ }^{2,6}$, Lenore Launer ${ }^{7}$, Farzaneh Sorond ${ }^{8}$, Sanaz Sedaghat ${ }^{9}$, Derek Wainwright ${ }^{10}$, Andrea Baccarelli ${ }^{11}$, Stephen Sidney ${ }^{12}$, Nick Bryan ${ }^{13}$, Philip Greenland ${ }^{1}$, Donald Lloyd-Jones ${ }^{1}$, Kristine Yaffe ${ }^{14,15,16,17, \#}$, Lifang Hou ${ }^{1, \#}$

${ }^{1}$ Department of Preventive Medicine, Northwestern University Feinberg School of Medicine, Chicago, IL 60611, USA

${ }^{2}$ Biggs Institute Neuroimaging Core, Glenn Biggs Institute for Neurodegenerative Disorders, University of Texas Health Science Center at San Antonio, San Antonio, TX 78229, USA

${ }^{3}$ Department of Radiology, University of Pennsylvania, Philadelphia, PA 19104, USA

${ }^{4}$ Division of Cardiology, Department of Medicine, Northwestern University Feinberg School of Medicine, Chicago, IL 60611, USA

${ }^{5}$ Feinberg Cardiovascular Research Institute, Northwestern University Feinberg School of Medicine, Chicago, IL 60611, USA

${ }^{6}$ Department of Neurology, Boston University School of Medicine, Boston, MA 02118, USA

${ }^{7}$ Laboratory of Epidemiology and Population Science, Intramural Research Program, National Institute on Aging, National Institutes of Health, Bethesda, MD 20892, USA

${ }^{8}$ Department of Neurology, Northwestern University Feinberg School of Medicine, Chicago, IL 60611, USA

${ }^{9}$ Division of Epidemiology and Community Health, School of Public Health, University of Minnesota, Minneapolis, MN 55455, USA

${ }^{10}$ Departments of Neurological Surgery, Medicine-Hematology and Oncology, Microbiology-Immunology, Northwestern University Feinberg School of Medicine, Chicago, IL 60611, USA

${ }^{11}$ Department of Environmental Health Sciences, Columbia University Mailman School of Public Health, New York, NY 10032, USA

${ }^{12}$ Kaiser Permanente Division of Research, Oakland, CA 94612, USA

${ }^{13}$ Department of Diagnostic Medicine, Dell Medical School, University of Texas at Austin, Austin, TX 78712, USA

${ }^{14}$ Department of Psychiatry and Behavioral Sciences, University of California San Francisco, CA 94143, USA

${ }^{15}$ Department of Neurology University of California, San Francisco, CA 94143, USA

${ }^{16}$ Department of Epidemiology and Biostatistics, University of California San Francisco, CA 94143, USA

${ }^{17}$ San Francisco VA Medical Center, San Francisco, CA 94143, USA

*Equal contribution

\#Co-senior author

Correspondence to: Yinan Zheng, Kristine Yaffe, Lifang Hou; email: y-zheng@northwestern.edu, Kristine.Yaffe@ucsf.edu, l-hou@northwestern.edu

Keywords: cognitive function, epigenetic age, brain age, DNA methylation, magnetic resonance imaging

Received: July 7, 2021

Accepted: February 8, 2022

Published: February 27, 2022

Copyright: (c) 2022 Zheng et al. This is an open access article distributed under the terms of the Creative Commons Attribution License (CC BY 3.0), which permits unrestricted use, distribution, and reproduction in any medium, provided the original author and source are credited.

\section{ABSTRACT}

The proportion of aging populations affected by dementia is increasing. There is an urgent need to identify biological aging markers in mid-life before symptoms of age-related dementia present for early intervention to delay the cognitive decline and the onset of dementia. In this cohort study involving 1,676 healthy participants 
(mean age 40) with up to 15 years of follow up, we evaluated the associations between cognitive function and two classes of novel biological aging markers: blood-based epigenetic aging and neuroimaging-based brain aging. Both accelerated epigenetic aging and brain aging were prospectively associated with worse cognitive outcomes. Specifically, every year faster epigenetic or brain aging was on average associated with 0.19-0.28 higher (worse) Stroop score, 0.04-0.05 lower (worse) RAVLT score, and 0.23-0.45 lower (worse) DSST (all falsediscovery-rate-adjusted $p$ <0.05). While epigenetic aging is a more stable biomarker with strong long-term predictive performance for cognitive function, brain aging biomarker may change more dynamically in temporal association with cognitive decline. The combined model using epigenetic and brain aging markers achieved the highest accuracy (AUC: $0.68, p<0.001$ ) in predicting global cognitive function status. Accelerated epigenetic age and brain age at midlife may aid timely identification of individuals at risk for accelerated cognitive decline and promote the development of interventions to preserve optimal functioning across the lifespan.

\section{INTRODUCTION}

By the year 2030, 75 to 82 million people worldwide are projected to be affected by dementia [1, 2]. Early diagnosis is valuable for timely management and intervention to delay or prevent cognitive decline and the onset of dementia [3-5]. Cognitive abilities decline with advancing age [6]. However, despite cumulative downward trajectories of cognition, prior studies have shown marked heterogeneity in the rate of decline across individuals [7-11]. This highlights the need for new approaches for the early detection of cognitive decline, based on biomarkers of systematic age-related biological degeneration including molecular aging markers in blood, as well as the degeneration directly in brain captured by structural brain imaging [12]. As both of these markers have high potential to inform and predict future cognitive status at the individual level, identifying biological bloodand imaging-based aging markers associated with cognitive function in mid-life, decades before symptoms of age-related dementia present, may aid in early detection of possible disease in people with mild symptoms, and facilitate the identification of vulnerable individuals before the onset of irreversible neuronal damage and extend opportunities for intervention.

Extensive basic science and epidemiological research have indicated that age-related cognitive decline is governed by interactions across genetic and environmental factors [13-15]. Epigenetics is a molecular marking system that reflects environmental and lifestyle factors [16]. DNA methylation (DNAm) is one of the most well-established epigenetic mechanisms linked to aging and aging-related diseases, [17] and it can be used to assess biological aging. The multi-tissue-derived Horvath's DNAm age and blood-derived Hannum's DNAm age are predictive of chronological age [18, 19]. More recently, newer blood-derived epigenetic aging models, such as DNAm Phenotypic Age (PhenoAge) [20] and GrimAge [21] have been developed that derive their DNAm predictions of life expectancy and risk of mortality from markers of physiological dysregulation. In particular, the latest GrimAge model can inform incident cardiovascular disease and all-cause mortality with stronger and more significant associations than earlier DNAm age measures [21].

While blood-derived epigenetic aging markers have shown predictive value years before age-related diseases occur [21-23]. biological aging rates can differ across organ systems, so predictors derived directly from the brain may hold unique information for cognition $[24,25]$. Across the lifespan, aging-related brain atrophy occurs in a predictable manner [26, 27]. Leveraging machine-learning algorithms, a composite age-related morphological index, Spatial Pattern of Atrophy for Recognition (SPARE) of Brain Age (SPARE-BA), has been developed to translate atrophy of brain structures into an aging marker [28-30]. As compared with resilient older adults, individuals with advanced imaging brain age have been found to display worse verbal fluency and attentional skills [10].

To study the portion of biological age that is not explained by chronological age, the concept of "age acceleration" has been proposed, [19] which quantifies the independent deviations of the biological age from chronological age. A positive value of age acceleration indicates that the biological age is higher than expected based on chronological age. The goal of the present study was to quantify the associations of epigenetic age acceleration and SPARE-BA acceleration with subsequent cognitive performance in a biracial cohort ( $\sim 40 \%$ Black participants and $\sim 60 \%$ White participants) of middle-aged adults with 5 to 15 years of follow up.

\section{RESULTS}

Epigenetic age, brain age, and cognitive function were measured twice at two consecutive visits (Figure 1). Table 1 shows the overall characteristics of the participants included in our study were representative of the total CARDIA population. The participants had a mean age of 50 and 55 at $\mathrm{Y} 25$ and Y30 visits, 
respectively, with approximately equal representation of both sex and racial groups. The participants included for epigenetic sub-study and brain MRI sub-study were not identical $(81 \%$ were not overlapped). However, participant characteristics across the epigenetic and brain aging analyses did not significantly differ, indicating comparable study samples between two sub- studies. Significant and moderate correlations were only observed across the epigenetic aging markers (GrimAA, PhenoAA, EEAA, and IEAA, see Methods) but the correlations were weak with SPARE-BAA. (Supplementary Figure 1). Epigenetic age and SPAREBA were both moderately correlated with chronological age (Pearson's r $=0.37$ to 0.55 , Supplementary Figure 2).

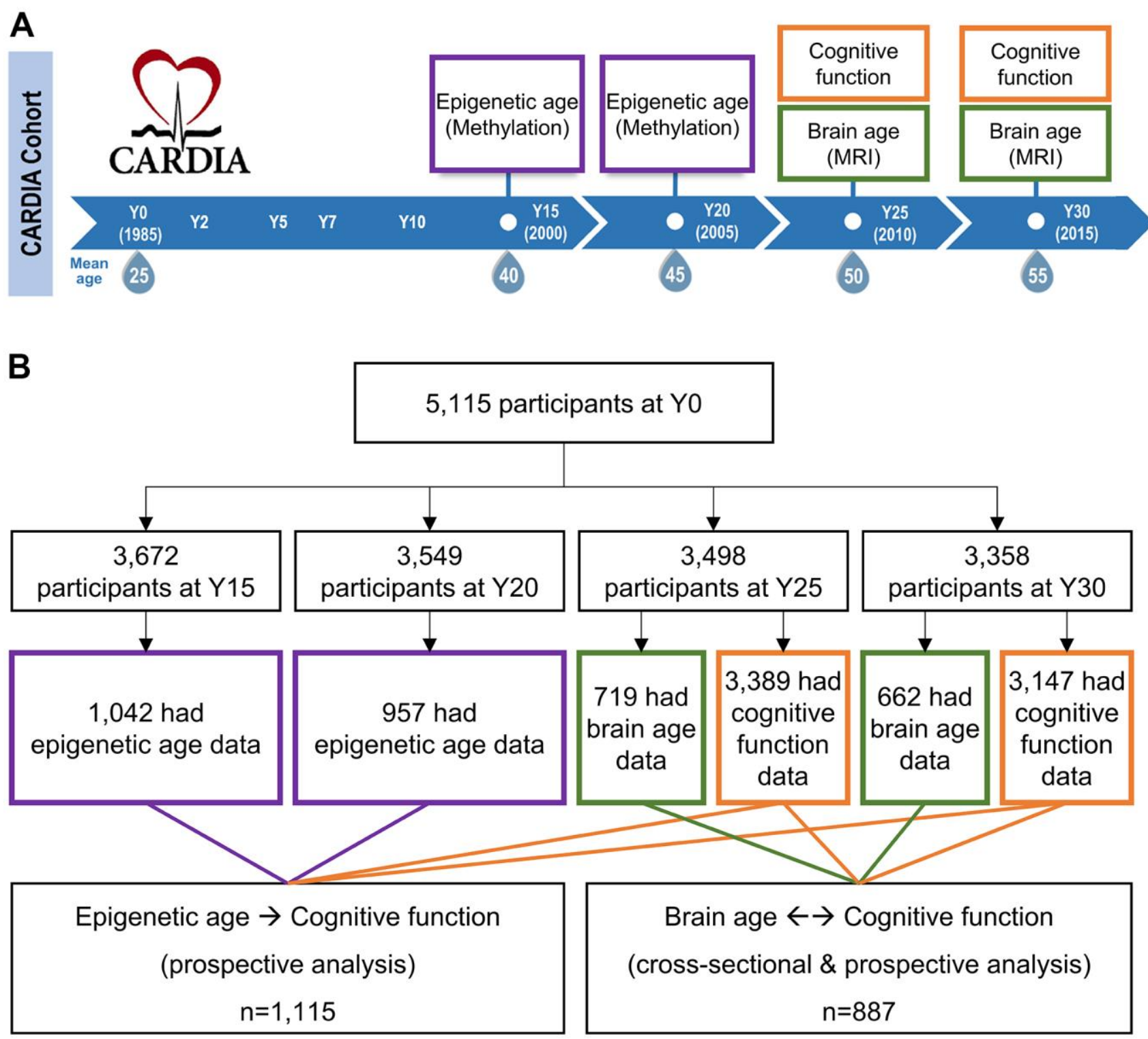

Figure 1. Study design and eligible study participants. (A) Epigenetic aging data were measured among a randomly selected subset of CARDIA participants at year (Y) Y15 and Y20. Brain aging data were measured at a subset of participants at Y25 and Y30. Cognitive function tests were performed at $\mathrm{Y} 25$ and $\mathrm{Y} 30$ across almost all CARDIA participants. The DNA methylation was measured at earlier visits before brain MRI because molecular changes could occur years before the brain structural changes. Besides, as a blood-based marker, epigenetic age can be cost-effectively measured at an earlier age. (B) Among the 1,042 Y15 and 957 Y20 participants who had methylation data, 881 had methylation data at both visits. Among the 719 Y 25 and 662 Y30 participants who had brain MRI data, 488 had MRI data at both visits. About 95\% of the CARDIA participants at Y25 and Y30 had cognitive function data. To maximize statistical power, those who had available DNA methylation and cognitive function data were eligible for epigenetic age analysis (a union set of 1,115 participants involved); those who had available brain MRI and cognitive function data were eligible for brain age analysis (a union set of 887 participants involved). There were 326 overlapping participants who had both DNA methylation and brain MRI data. 
Table 1. Characteristics of study participants at year 25 and Y30.

\begin{tabular}{|c|c|c|c|c|}
\hline $\begin{array}{l}\text { Characteristics } \\
\text { mean (SD) / count }(\%)\end{array}$ & $\begin{array}{l}\text { All CARDIA participants } \\
(\text { Y25 and Y30) } \\
(\mathbf{n}=\mathbf{3 , 7 2 6})\end{array}$ & $\begin{array}{c}\text { Epigenetic age and } \\
\text { cognitive function } \\
\text { analysis } \\
(\mathbf{n}=\mathbf{1 , 1 1 5}) \\
\end{array}$ & $\begin{array}{c}\text { Brain age and } \\
\text { cognitive } \\
\text { function analysis } \\
(\mathbf{n}=\mathbf{8 8 7}) \\
\end{array}$ & p-value ${ }^{1}$ \\
\hline Age (Y25, year) & $50.2(3.6)$ & $50.3(3.5)$ & $50.2(3.5)$ & 0.396 \\
\hline Age (Y30, year) & $55.1(3.6)$ & $55.4(3.5)$ & $55.2(3.6)$ & 0.349 \\
\hline \multicolumn{5}{|l|}{$\operatorname{Sex}(\%)$} \\
\hline Female & $2104(56.5)$ & $559(50.1)$ & $466(52.5)$ & \multirow{2}{*}{0.134} \\
\hline Male & $1621(43.5)$ & $556(49.9)$ & $421(47.5)$ & \\
\hline \multicolumn{5}{|l|}{$\operatorname{Race}(\mathbf{N}, \%)$} \\
\hline Black & $1781(47.8)$ & $454(40.7)$ & $368(41.5)$ & \multirow{2}{*}{0.604} \\
\hline White & $1945(52.2)$ & $661(59.3)$ & $519(58.5)$ & \\
\hline \multicolumn{5}{|l|}{ Education $(\mathrm{N}, \%)$} \\
\hline High school or less & $780(20.9)$ & $241(21.6)$ & $193(21.8)$ & \multirow{3}{*}{0.361} \\
\hline Some college & $960(25.8)$ & $297(26.6)$ & $256(28.9)$ & \\
\hline College graduate or higher & $1710(45.9)$ & $577(51.7)$ & $438(49.3)$ & \\
\hline \multicolumn{5}{|l|}{ Study field center $(\mathrm{N}, \%)$} \\
\hline Birmingham & $871(23.4)$ & $269(24.1)$ & $239(26.9)$ & \multirow{4}{*}{$<0.001$} \\
\hline Chicago & $833(22.4)$ & $248(22.2)$ & - & \\
\hline Minneapolis & $978(26.2)$ & $288(25.8)$ & 354 (39.9) & \\
\hline Oakland & $1044(28.0)$ & $310(27.9)$ & $294(33.2)$ & \\
\hline Stroop test (Y25) & $22.8(10.8)$ & $22.7(10.9)$ & $22.3(9.6)$ & 0.373 \\
\hline Stroop test (Y30) & $23.0(11.7)$ & $22.5(11.8)$ & $22.2(11.4)$ & 0.782 \\
\hline RAVLT (Long delay recall, Y25) & $8.3(3.3)$ & $8.4(3.2)$ & $8.4(3.3)$ & 0.585 \\
\hline RAVLT (Long delay recall, Y30) & $8.5(3.4)$ & $8.7(3.3)$ & $8.8(3.4)$ & 0.685 \\
\hline DSST (Y25) & $69.9(16.2)$ & $70.6(16.1)$ & $70.0(15.6)$ & 0.381 \\
\hline DSST (Y30) & $67.4(17.0)$ & $68.5(16.2)$ & $68.5(16.3)$ & 0.890 \\
\hline
\end{tabular}

${ }^{1}$ Comparisons between epigenetic age analysis and brain age analysis. P-values were calculated based on t-test for continuous variables and chi-square test for categorical variables. The epigenetic age analysis and brain age analysis involved different yet overlapping CARDIA participants. These overlapping participants $(n=326)$ were removed from the test to ensure the data independence between the comparison groups.

Higher GrimAA was significantly associated with lower subsequent cognitive performance across all three cognitive measures (Table 2). The strength of the associations with cognitive outcomes was evident and similar in both short-term (5-year) and long-term (15year) prospective analyses, as a result, the 5-year delta association analysis did not yield any significant results, indicating that GrimAA had a persistent, stable prospective association with cognition. IEAA, EEAA, PhenoAA were not associated with any cognitive measures (Supplementary Table 1). For brain aging, higher SPARE-BAA was associated with lower cognitive performance (Table 3 ). We observed stronger and more significant cross-sectional associations between SPARE-BAA and cognitive function at Y30 (mean age 55) than at Y25 (mean age 50). SPAREBAA also had prospective associations with cognitive measures 5 years later. Although the 5-year delta analyses did not yield significant association, the directions of associations were consistent with crosssectional and prospective analyses.

We further evaluated the associations between the 5-year changes of age markers over time (Y15 to Y20 for epigenetic age, Y25 to Y30 for brain age) and cognitive function at Y30. Consistent with the 5-year delta association analyses, faster rate of change in SPARE-BA over time, but not any of the epigenetic age markers, was significantly associated with worse performance in the Stroop test (false discovery rate $(\mathrm{FDR})=0.007)$ and DSST (FDR=0.033) (Supplementary Table 2).

Given the significant associations of GrimAA and SPARE-BAA with cognitive function, we further evaluated the effect modifications of sex and carrier status for the APOE4 allele. We observed that compared to men, women were more likely to yield stronger associations between GrimAA and cognitive function, especially 
Table 2. Association between GrimAA and cognitive function.

\begin{tabular}{|c|c|c|c|c|c|c|c|c|c|c|c|c|}
\hline \multirow[b]{2}{*}{ Analysis type } & \multicolumn{4}{|c|}{ Stroop test } & \multicolumn{4}{|c|}{ RAVLT long delay recall } & \multicolumn{4}{|c|}{ DSST } \\
\hline & $\begin{array}{c}\text { Coefficient } \\
\text { (95\% CI) }\end{array}$ & $\mathbf{p}$ & Adj.p ${ }^{1}$ & $\mathbf{n}$ & $\begin{array}{c}\text { Coefficient } \\
(95 \% \text { CI })\end{array}$ & $\mathbf{p}$ & Adj.p ${ }^{1}$ & $\mathbf{n}$ & $\begin{array}{c}\text { Coefficient } \\
\text { (95\% CI) }\end{array}$ & $\mathbf{p}$ & Adj.p ${ }^{1}$ & $\mathbf{n}$ \\
\hline $\begin{array}{l}\text { 5-year prospective } \\
\text { analysis } \\
\text { (Y20 epigenetic aging vs. } \\
\text { Y25 Cognition) }\end{array}$ & $\begin{array}{c}0.194 \\
(0.050,0.338)\end{array}$ & 0.009 & 0.013 & 925 & $\begin{array}{c}-0.046 \\
(-0.087,-0.005)\end{array}$ & 0.028 & $\mathbf{0 . 0 2 8}$ & 932 & $\begin{array}{c}-0.308 \\
(-0.505,-0.110)\end{array}$ & 0.002 & 0.007 & 931 \\
\hline $\begin{array}{l}\text { 15-year prospective } \\
\text { analysis }{ }^{2} \\
\text { (Y15 epigenetic aging vs. } \\
\text { Y30 Cognition) }\end{array}$ & $\begin{array}{c}0.231 \\
(0.069,0.394)\end{array}$ & 0.005 & 0.008 & 890 & $\begin{array}{c}-0.048 \\
(-0.091,-0.005)\end{array}$ & 0.029 & 0.029 & 905 & $\begin{array}{c}-0.404 \\
(-0.614,-0.195)\end{array}$ & $<0.001$ & $<0.001$ & 906 \\
\hline $\begin{array}{l}\text { Delta analysis } \\
\text { (5-year change in } \\
\text { GrimAA vs. 5-year } \\
\text { change in cognition) }\end{array}$ & $\begin{array}{c}0.006 \\
(-0.159,0.170)\end{array}$ & 0.946 & 0.946 & 741 & $\begin{array}{c}0.049 \\
(0.000,0.098)\end{array}$ & 0.049 & 0.147 & 754 & $\begin{array}{c}0.076 \\
(-0.093,0.245)\end{array}$ & 0.380 & 0.569 & 754 \\
\hline
\end{tabular}

${ }^{1} \mathrm{BH}-F D R$ adjustment was applied to account for multiple testing for each aging marker across all the cognitive function tests. ${ }^{2}$ Multiple linear regression models adjusting for age, sex, race, study fields, and education. Beta coefficients indicate changes in cognitive function score by one year greater in GrimAA.

Table 3. Association between SPARE-BAA and cognitive function.

\begin{tabular}{|c|c|c|c|c|c|c|c|c|c|c|c|c|}
\hline \multirow[b]{2}{*}{ Analysis type } & \multicolumn{4}{|c|}{ Stroop test } & \multicolumn{4}{|c|}{ RAVLT long delay recall } & \multicolumn{4}{|c|}{ DSST } \\
\hline & $\begin{array}{c}\text { Coefficient } \\
(95 \% \text { CI })\end{array}$ & $\mathbf{p}$ & Adj.p ${ }^{1}$ & $\mathbf{n}$ & $\begin{array}{c}\text { Coefficient } \\
(95 \% \text { CI })\end{array}$ & $\mathbf{p}$ & Adj.p ${ }^{1}$ & n & $\begin{array}{c}\text { Coefficient } \\
(95 \% \text { CI })\end{array}$ & $\mathbf{p}$ & Adj.p ${ }^{1}$ & $\mathbf{n}$ \\
\hline $\begin{array}{l}\text { Cross-sectional } \\
\text { analyses } \\
\text { (Y25 SPARE-BAA vs. } \\
\text { Y25 Cognition) }\end{array}$ & $\begin{array}{c}0.043 \\
(-0.054,0.141)\end{array}$ & 0.382 & 0.382 & 704 & $\begin{array}{c}-0.036 \\
(-0.068,-0.005)\end{array}$ & 0.024 & $\mathbf{0 . 0 3 7}$ & 704 & $\begin{array}{c}-0.229 \\
(-0.378,-0.080)\end{array}$ & 0.003 & 0.008 & 707 \\
\hline $\begin{array}{l}\text { Cross-sectional } \\
\text { analyses }^{2} \\
\text { (Y30 SPARE- BAA vs. } \\
\text { Y30 Cognition) }\end{array}$ & $\begin{array}{c}0.283 \\
(0.158,0.408)\end{array}$ & $<0.001$ & $<0.001$ & 615 & $\begin{array}{c}-0.042 \\
(-0.078,-0.007)\end{array}$ & 0.021 & 0.021 & 620 & $\begin{array}{c}-0.448 \\
(-0.609,-0.287)\end{array}$ & $<0.001$ & $<\mathbf{0 . 0 0 1}$ & 623 \\
\hline $\begin{array}{l}\text { Prospective analyses }^{2} \\
\text { (Y25 SPARE- BAA vs. } \\
\text { Y30 Cognition) }\end{array}$ & $\begin{array}{c}0.151 \\
(0.022,0.279)\end{array}$ & 0.022 & $\mathbf{0 . 0 3 3}$ & 630 & $\begin{array}{c}-0.031 \\
(-0.067,0.004)\end{array}$ & 0.086 & 0.086 & 641 & $\begin{array}{c}-0.274 \\
(-0.438,-0.111)\end{array}$ & 0.001 & 0.003 & 644 \\
\hline Mixed-effects model $^{3}$ & $\begin{array}{c}0.144 \\
(0.059,0.230)\end{array}$ & 0.001 & 0.002 & 1319 & $\begin{array}{c}-0.038 \\
(-0.064,-0.012)\end{array}$ & 0.004 & 0.004 & 1324 & $\begin{array}{c}-0.266 \\
(-0.383,-0.149)\end{array}$ & 0.000 & $<0.001$ & 1330 \\
\hline $\begin{array}{l}\text { Delta analysis } \\
\text { (5-year change in } \\
\text { SPARE-BAA vs. 5-year } \\
\text { change in cognition) }\end{array}$ & $\begin{array}{c}0.218 \\
(-0.012,0.448)\end{array}$ & 0.064 & 0.193 & 466 & $\begin{array}{c}-0.028 \\
(-0.096,0.041)\end{array}$ & 0.430 & 0.644 & 472 & $\begin{array}{c}-0.056 \\
(-0.308,0.196)\end{array}$ & 0.663 & 0.663 & 472 \\
\hline
\end{tabular}

${ }^{1} \mathrm{BH}-F D R$ adjustment was applied to account for multiple testing for each aging marker across all the cognitive function tests.

${ }^{2}$ Multiple linear regression models adjusting for age, sex, race, study fields, and education. Beta coefficients indicate changes in cognitive function score by one year greater in SPARE-BAA.

${ }^{3}$ Mixed-effects model with random intercept incorporating SPARE-BAA at Y25 and Y30, and cognitive function at Y25 and Y30.

Stroop test and DSST (Supplementary Table 3), although the interaction tests were not significant after multiple comparison adjustment.

APOE4 genotype, on the other hand, has been shown to increase the risk of Alzheimer's disease and lowers the age of disease onset [31]. GrimAA was greater than 0 among those who were homozygous for APOE4 (APOE
4/4) and higher than the non-carrier (APOE 3/3) and heterozygous (APOE 4/3) but not statistically significant (Supplementary Figure 3). SPARE-BAA was roughly equal across three genotype groups. No significant differences were observed after stratifying the association analyses of GrimAA and SPARE-BAA with cognitive function by non-carrier ( $A P O E 3 / 3$ ) vs. carriers (APOE $4 / 3$ or $4 / 4$ ) (Supplementary Table 4). 
Due to the weak correlations between GrimAA and SPARE-BAA (Pearson's $r=0.04-0.18$ ), as well as the strong associations with cognition observed for GrimAA and SPARE-BAA, in particular, we opted to select GrimAA and SPARE-BAA to further explore their additive predictive performance in discriminating future global cognitive status at Y30. Global cognitive status was constructed as a composite score from the first principle components (PC1) of all the three cognitive test scores (see Materials and Methods). PC1 was significantly correlated with all cognitive tests ( $\mathrm{p}<0.001)$ with higher PC1 values indicating better cognitive performance (Supplementary Figure 4). As a baseline marker, chronological age showed a significant association with global cognitive status $(\mathrm{OR}=1.07$ per year older, 95\%CI: $1.03-1.11$, p <0.001) but discrimination was poor $(\mathrm{AUC}=0.54,95 \% \mathrm{CI}$ : 0.47-0.53). Every year greater in Y15 and Y20 GrimAA was associated with 1.06 higher odds of low global cognitive status (95\% CI: 1.02-1.10; $\mathrm{p}=0.002$, Figure 2A). SPARE-BAA at $\mathrm{Y} 30$ had a more significant association with global cognitive status than Y25 (Figure 2B). GrimAA (AUC $=0.64-0.65$ ) achieved better predictive performance than SPAREBAA (AUC 0.51-0.55). Although SPARE-BAA alone did not demonstrate discrimination values, combining GrimAA at Y20 and SPARE-BAA at Y30 produced the highest AUC in distinguishing between future high and low global cognition at Y30 (AUC $=0.68,95 \% \mathrm{CI}$ : 0.61-0.76).

\section{DISCUSSION}

The current study evaluated two classes of new biological aging biomarkers, epigenetic aging and brain aging, as predictors of cognition in a biracial middleaged population-based cohort. Our results support growing literature indicating that accelerated GrimAge is a robust predictor of adverse health outcomes across both the peripheral and central nervous systems [21, 32, 33]. Additionally, accelerated brain age (as measured via SPARE-BAA) was both cross-sectionally and prospectively associated with lower performance in multiple cognitive domains. GrimAA and SPARE-BAA were not correlated with one another, indicating that they capture distinct facets of biological aging. A combined model with GrimAA and SPARE-BAA improved predictive performance for lower global cognitive status at Y30. Overall, the results indicate that GrimAA and SPARE-BAA are potentially useful indicators of worse cognitive outcomes at midlife- a period in which interventions for preventing irreversible cognitive impairment may be most beneficial [34].

GrimAA was associated with worse cognitive performance across domains and time intervals. Multiple studies have demonstrated GrimAA's relevance as a biological marker for advanced cognitive aging [33, 35, 36]. McCrory et al. examined the associations of IEAA, EEAA, PhenoAA, and GrimAA with performance on cognitive screening tasks in the
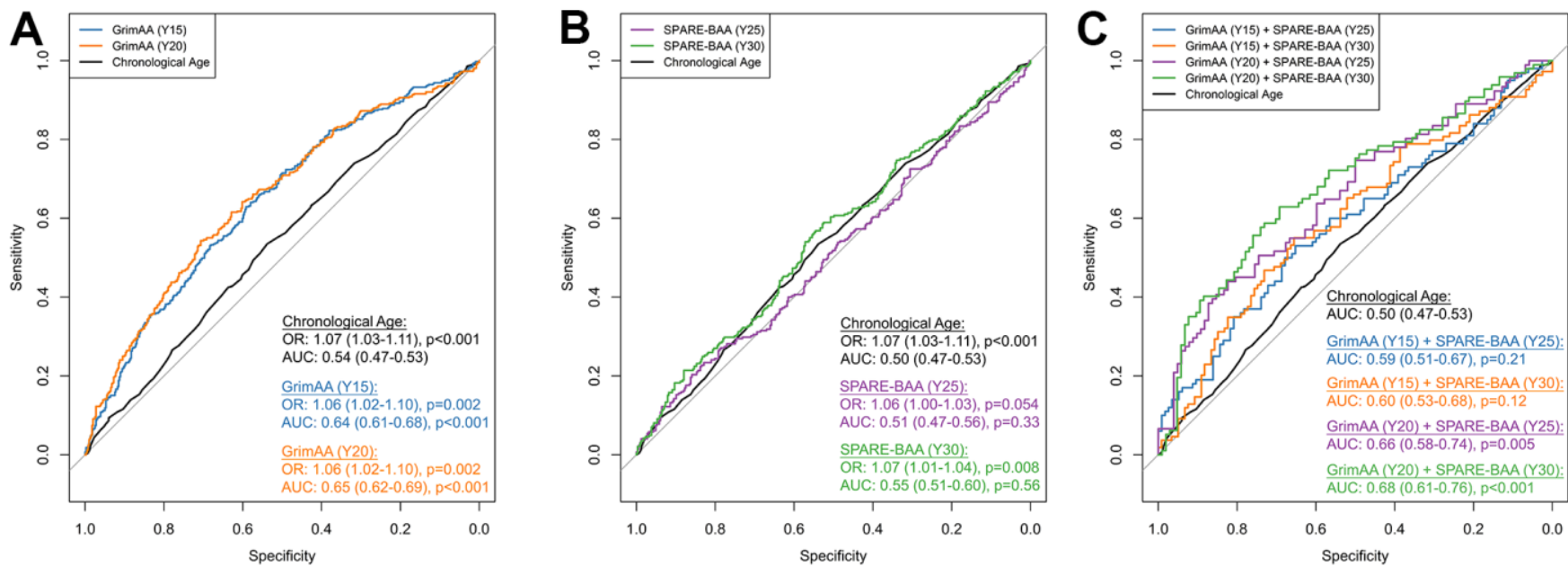

Figure 2. ROC curves of GrimAA (A) SPARE-BAA (B) and their joint modeling (C) in predicting global cognitive status at Y30. The median of the first principal component of Stroop, RAVLT (long delay recall), and DSST test scores (i.e., global cognitive function) measured at Y30 was used to dichotomize the global cognitive status into low (denote by 1 ) vs. high (denote by 0 ). The ROC curves were generated using $80 / 20$ training/testing sets with 5-fold cross-validation to avoid overfitting. Associations between two aging markers and Y30 cognitive status evaluated by logistic regression were presented as odds ratio (OR) with every one year greater in GrimAA/SPARE-BAA, adjusting for age, sex, race, study fields, and education. The p-values of AUC were calculated by comparing with the chronological age benchmark AUC curve. GrimAA: GrimAge acceleration; SPARE-BAA: SPARE-BA acceleration; OR: odds ratio; AUC: area under the ROC curve. 
Irish Longitudinal Study of Ageing, a study of community-dwelling older people in Ireland [32]. Similar to the current results, GrimAA was the only epigenetic aging marker associated with worse cognitive performance. In the Lothian Birth Cohort 1936, GrimAA was found to have significant associations with an array of neurologically-relevant outcomes including worse general cognition, slowed processing speed, and lower perceptual organization scores [33]. Maddock et al. reported that GrimAA predicted decline in verbal memory and processing speed across a 16-year interval [35]. In our study, GrimAA demonstrated largely stable associations with cognitive outcomes over time, highlighting its potential utility for advancing early detection of cognitive vulnerability. Different from the earlier versions of epigenetic age biomarkers, GrimAA is a composite biomarker consisting of blood DNAm surrogates of smoking pack-years as well as seven plasma proteins that are associated with various agerelated conditions, including adrenomedullin, $\beta 2$ microglobulin, cystatin $\mathrm{C}$, growth differentiation factor15, plasminogen activator inhibitor 1, leptin, and tissue inhibitor metalloproteinase-1 [21]. All of these plasma proteins, together with smoking, have been shown to be associated with cognitive impairment and Alzheimer's disease [37-44]. This is also supported by the significant correlations between the 8 DNAm surrogate components of GrimAA and the 3 cognitive tests in our data (Supplementary Figure 5), which may explain why GrimAA outperformed the other epigenetic age biomarkers in our study.

SPARE-BAA was cross-sectionally and prospectively associated with cognition. In alignment with SPAREBA's summarized atrophy pattern with predilection for rostral brain structures, [29] the measure was most strongly associated with tests heavily reliant on frontal lobe function [45, 46]. Cross-sectional analyses demonstrated more robust cognitive associations at Y30 as compared with Y25, suggesting greater sensitivity within older age groups. This observation may help explain the divergence of our results with a prior study that reported null associations between SPARE-BA and cognition when examining a cohort spanning from early adulthood to late-life (20-90 years) [29]. More consistent with the current findings, a study of older adults (50-96 years) reported worse executive function and attentional abilities in the advanced brain aging group with the most significant gray matter atrophy [10]. Future research with broader age ranges is necessary to fully evaluate the potential of time-varying associations of advanced brain aging.

Despite the loss of statistical significance after accounting for multiple comparison, we observed a general trend that women were more likely to yield stronger and more significant associations, particularly for Stroop test and DSST (Supplementary Table 3). This is in line with a recent multi-cohort population study with 34,349 US adults, [47] which suggested that women may experience faster cognitive decline than men- an equivalent to about 5 years faster of cognitive aging. We did not observe significant interactions between APOE4 and both age acceleration markers. This may be due to the relatively younger population we studied, where the impact of APOE4 has not yet presented. Evidence has shown that the differences between APOE4 carriers vs. non-carriers in terms of cognitive ability can become more pronounced with older age [48]. The generally more significant results among the APOE non-carrier group we observed may result from more participants (about doubled) than the carrier. Future studies may consider larger sample size when studying this topic among younger population.

GrimAA had a stronger predictive performance for cognition than SPARE-BAA. However, changes in the SPARE-BA and SPARE-BAA index over time showed stronger associations with cognition than the changes in any types of epigenetic age over time, suggesting that it may change more dynamically in temporal association with cognitive decline. Age-related cognitive decline is precipitated by changes in synaptic morphology and function [49]. Structural atrophy develops subsequent to the synaptic changes, [50] which may help explain SPARE-BAA's weaker prognostic significance for cognition in our middle-aged sample. Early changes in synaptic structure and function are associated with alterations in gene expression, which are governed in part by epigenetics [5]. Prior research has indicated both distinct and overlapping epigenetic changes in blood and brain tissue [24]. Consistent with a previous study, [51] blood-derived epigenetic aging may have some, correspondence with epigenetic processes in the brain. Alternatively, as a predictor of multi-organ dysregulation [21], GrimAA may reflect broad homeostatic dysfunction and inflammation capable of inducing adverse outcomes across the peripheral and central nervous systems. GrimAA was weakly correlated with SPARE-BAA, which is consistent with a previous study that bloodbased epigenetic age markers may not be well calibrated for measuring biological aging of the brain [52]. Hence, a combined model with both GrimAA and SPARE-BAA had an improved predictive performance for cognitive function, suggesting that they may provide complementary information relevant to accelerated cognitive aging. Despite our ROC curve analyses were robust by using the 80/20 data split and cross-validation, we would like to point out that given the limited sample size of those who had both DNAm data and brain MRI data, this analysis was still exploratory and should be interpreted with caution. 
While our study has many strengths, including a large, racially diverse sample and 15 years of longitudinal data collection, the limitations of the study must be considered when interpreting the results. First, epigenetic and brain imaging markers were largely derived from different study participants. While the two subsets of participants had similar demographics and cognitive performance, there may be unmeasured factors that could contribute to bias in the results. Additionally, cognitive function at younger ages was not available, and epigenetic markers were collected at different time points than cognitive and neuroimaging outcomes. Thus, we are unable to evaluate crosssectional associations with epigenetic aging and cannot directly compare epigenetic and brain aging markers collected at the same time points. Despite this limitation, outcomes with epigenetic markers were generally stable across the timepoints assessed and predictive of cognitive function 10 years later, indicating a long-term marker of aging. Finally, this study in CARDIA had a limited window on the lifespan, and the associations we observed may differ or be better captured at older ages. Future studies conducted in longer follow-up periods will be necessary to evaluate the relative efficacy of epigenetic and brain aging markers for predicting preclinical neurodegenerative disease and incident dementia.

In conclusion, across the four epigenetic aging markers examined, GrimAA was unique in its ability to predict worse cognitive outcomes in our middle-aged CARDIA population. A separate class of biological aging markers derived from neuroimaging outcomes also demonstrated cross-sectional and prospective associations with cognition. Epigenetic aging and brain aging markers may capture distinct facets of cognitive aging. A combined model with epigenetic (GrimAA) and brain (SPARE-BAA) aging markers improved predictive performance for lower cognitive performance. Overall, the results showcase the prognostic significance of biological aging markers for cognitive health. With further validation, epigenetic and brain aging markers may help aid timely identification of individuals at risk for accelerated cognitive decline and promote the development of interventions to preserve optimal functioning across the lifespan.

\section{MATERIALS AND METHODS}

\section{Study sample}

DNA methylation and brain MRI data were generated and re-analyzed in two separate sub-studies in the Coronary Artery Risk Development in Young Adults study (CARDIA), a prospective, multi-center cohort. In 1985-1986, 5,115 self-identified Black and White men and women ages 18-30 were recruited from four urban sites in the US: Birmingham, Chicago, Minneapolis, and Oakland. CARDIA's initial sample was approximately balanced with respect to race, sex, age, education, and study site. CARDIA participants have been followed for over 30 years with high retention rates $(>70 \%$ of surviving participants attending each inperson examination) [53]. Additional details regarding study design and recruitment, and participant characteristics at baseline, have been reported previously [54]. Our study used data collected from examination Year (Y) 15, Y20, Y25, and Y30 (Figure 1A). DNAm was measured at earlier visits before brain magnetic resonance imaging (MRI) because molecular changes could occur years before the brain structural changes. Besides, as a blood-based marker, epigenetic age can be cost-effectively measured at an earlier age. To maximize statistical power, we utilized all participants $(n=1,676)$ with available data for the corresponding association analyses, which involved 1,115 participants in epigenetic age analysis and 887 participants in brain age analysis (Figure 1B). CARDIA was approved by the institutional review boards at all study sites, and all participants provided written informed consent, including for the collection of DNA from blood.

\section{DNA sample collection and DNAm profiling}

Overnight fasting blood samples were collected in EDTA tubes. DNA was extracted using a PureGene DNA extraction kit (Gentra Systems) and stored at $-70^{\circ} \mathrm{C}$. Among 3,672 and 3,549 individuals in CARDIA who attended both examinations at Year (Y) 15 and Y20, respectively, we randomly selected 1,200 individuals for DNAm profiling at each examination to achieve a balance sampling within four strata of race and sex from the four CARDIA field centers. Raw DNAm data were preprocessed, QCed, and normalized (Supplementary Methods). Under the stringent QC criteria, we excluded 158 and 243 participants who had low-quality DNA or DNAm data at Y15 and Y20, respectively.

\section{Epigenetic age acceleration}

Epigenetic age estimates were calculated online at https://dnamage.genetics.ucla.edu/new [19]. We generated four epigenetic age estimates at both Y15 and Y20 visits: DNAm GrimAge [21], DNAm PhenoAge [23], Hannum's DNAm Age, [18] and Horvath's DNAm Age [19]. We calculated the corresponding acceleration measures, GrimAge Acceleration (GrimAA), PhenoAge Acceleration (PhenoAA), Extrinsic Epigenetic Age Acceleration (EEAA), and Intrinsic Epigenetic Age Acceleration 
(IEAA), which are defined as the residuals of a linear model of the corresponding epigenetic age regressed on chronological age and thus independent of chronological age [19].

\section{Brain MRI measures}

Among 3,498 and 3,358 individuals in CARDIA who attended at Y25 and Y30, respectively, 719 at Y25 and 663 at Y30 participated in the CARDIA Brain MRI Sub-study. Exclusion criteria of the MRI Sub-study included contraindication to MRI, possible pregnancy, or a body size that was too large for the MRI tube bore $[4,55]$. The participants selected for the CARDIA Brain MRI Sub-study achieved a balance sampling within four strata of race and sex from three of the CARDIA field centers: Birmingham,, Minneapolis, and Oakland. Brain MRI was performed using 3T MR scanners at three CARDIA study field sites (Siemens 3T Tim Trio/VB 15 platform at Oakland and Minneapolis sites, and Philips 3T Achieva/2.6.3.6 platform at Birmingham site). MRI data were transferred to the reading center at the University of Pennsylvania (Section of Biomedical Image Analysis, Department of Radiology) for standardized data processing following quality assurance protocols which have been previously described [55].

\section{Spatial Patterns of Abnormality for REcognition (SPARE) machine learning-based indices}

Among the individuals who underwent brain MRI, we computed the SPARE indices in CARDIA using a previously trained and validated model [28] for all 719 individuals at Y25 and 662 individuals at Y30 (one participant was excluded due to poor MRI data quality) using T1 imaging data and machine learning methods that have been extensively validated in other cohorts $[11,28-30,56]$. Briefly, the SPARE-Brain Age (BA) $[10,29,56]$ represents the predicted brain age from a model trained by brain MRI data of cognitively normal individuals from the iSTAGING consortium [56] and harmonized with CARDIA (Supplementary Methods). Similar to DNAm age acceleration, we calculated SPARE-BA acceleration (SPARE-BAA) using the residuals of a linear model of SPARE-BA regressed on chronological age.

\section{Cognitive tests}

A battery of standardized tests to measure cognitive function was first administered in over $90 \%$ of the CARDIA participants at the Y25 $(\mathrm{n}=3,389)$ and Y30 $(\mathrm{n}=3,147)$ visits. This included 1$)$ the Stroop Color and Word Test (Stroop), which evaluates the ability to respond to one stimulus dimension while suppressing the response to another dimension (lower score the better)- an "executive" skill largely attributed to frontal lobe function; [3] 2) the Rey Auditory Verbal Learning Test (RAVLT), which assesses the ability to learn and to recall words (verbal memory) [57]. Results from long delay $(10 \mathrm{~min})$ free recall were considered in our analysis with higher scores indicating better performance (range 0-15); and 3) the Digital Symbol Substitution Test (DSST), a subtest of the Wechsler Adult Intelligence Scale ( ${ }^{\text {rd }}$ edition) that assesses visual-motor speed, sustained attention, and working memory, [58] with higher scores indicating better performance (range 0-133).

\section{APOE genotyping}

APOE genotyping was determined from plasma samples collected at Year 7 examination (1992-1993) by isoelectric focusing and immunoblotting, described previously by Kataoka et al. [59].

\section{Statistical analysis}

All statistical analyses were performed with $\mathrm{R}$ (version 4.0.0). Characteristics of participants were compared with Student's t-test for continuous variables and chisquare test for categorical variables. We evaluated the pair-wise correlations between epigenetic aging markers and SPARE-BAA using Pearson's correlation coefficient $(r)$. We used multiple linear regression models with epigenetic aging markers or SPARE-BAA treated as independent variables and cognitive tests as dependent variables. For SPARE-BAA, we used mixed-effects model with a random intercept to accounts for the repeated measures of SPARE-BA and cognitive function at Y25 and Y30. For SPARE-BAA, we used mixedeffects model with a random intercept to accounts for the repeated measures of SPARE-BA and cognitive function at both Y25 and Y30. For each marker, p-values of the associations across the cognitive tests were adjusted for multiple testing using Benjamini-Hochberg False Discovery Rate (FDR) [60]. All models were adjusted for age, sex, race, study site, and education as covariates. We constructed a composite global cognitive function score using the first principal component (PC1) [61] across the Y30 cognitive tests: Stroop test, RAVLT long delay recall, and DSST. We dichotomized the PC1 using its median to define high (coded as 0 ) vs. low (coded as 1) global cognitive status. Global cognitive status at Y30 was predicted with logistic regression and tested the odds ratio (OR) using biological aging markers, i.e., epigenetic age acceleration markers at Y15/Y20 and SPARE brain metrics at $\mathrm{Y} 25 / \mathrm{Y} 30$, adjusting for the covariates mentioned above. To evaluate the additive predictive performance of both epigenetic age acceleration and SPARE brain metrics, we performed receiver operating 
characteristic (ROC) curve analysis by modeling both aging markers together. All ROC results were performed based on a 5-fold cross-validation (i.e., 80/20 ratio training/testing dataset split) to avoid overfitting. We used $\mathrm{R}$ package pROC to estimate $95 \%$ confidence intervals (CI) of the area under the ROC curves (AUC) with DeLong test and to compare AUC between two curves with bootstrap test [62].

\section{Abbreviations}

CARDIA: Coronary Artery Risk Development in Young Adults study; RAVLT: Rey Auditory Verbal Learning Test; DSST: Digital Symbol Substitution Test; GrimAA: GrimAge Acceleration; PhenoAA: PhenoAge Acceleration; EEAA: Extrinsic Epigenetic Age Acceleration; IEAA: Intrinsic Epigenetic Age Acceleration; MRI: Magnetic Resonance Imaging; SPARE: Spatial Patterns of Abnormality for Recognition; BAA: Brain Age Acceleration; FDR: False Discovery Rate; OR: Odds Ratio; ROC: Receiver Operating Characteristic; CI: Confidence Intervals; AUC: Area Under the ROC Curve.

\section{AUTHOR CONTRIBUTIONS}

M.H., Y.Z., and L.H. conceived the original idea and designed the study. Y.Z., M.H., and S. Sedaghat performed the statistical data analysis. Y.Z. D.L., and L.H. contributed to the epigenetic age calculation. M.H., M.G., R.P., I.N., C.D., S. Seshadri, L.L., and N.B. contributed to the brain age calculation. Y.Z., M.H., and M.G. wrote the first draft of the manuscript. F.S., S. Sedaghat, D.K., A.B., S.S., K.Y., N.B., P.G., D.L., and L.H. contributed to interpreting the results and provided critical revisions on the manuscript. All authors discussed the results and contributed to the final manuscript.

\section{CONFLICTS OF INTEREST}

The authors declare that they have no conflicts of interest.

\section{FUNDING}

The study was funded by NIH/NIA grant R01AG069120. The Coronary Artery Risk Development in Young Adults Study (CARDIA) is conducted and supported by the National Heart, Lung, and Blood Institute (NHLBI) in collaboration with the University of Alabama at Birmingham (HHSN268201800005I and HHSN2682018 00007I), Northwestern University (HHSN2682018000 03I), University of Minnesota (HHSN268201800006I), and Kaiser Foundation Research Institute (HHSN 268201800004I). CARDIA was also partially supported by the Intramural Research Program of the National Institute on Aging (NIA) and an intra-agency agreement between NIA and NHLBI (AG0005). The DNA methylation laboratory work and analytical component were funded by American Heart Association (17SFRN33700278 and 14SFRN20790000, Northwestern University, PI: Dr. Lifang Hou). This manuscript has been reviewed by CARDIA for scientific content.

\section{REFERENCES}

1. Winblad B, Amouyel P, Andrieu S, Ballard C, Brayne C, Brodaty $\mathrm{H}$, Cedazo-Minguez A, Dubois B, Edvardsson D, Feldman H, Fratiglioni L, Frisoni GB, Gauthier S, et al. Defeating Alzheimer's disease and other dementias: a priority for European science and society. Lancet Neurol. 2016; 15:455-532. https://doi.org/10.1016/S1474-4422(16)00062-4 PMID:26987701

2. Dua T, Seeher KM, Sivananthan S, Chowdhary N, Pot AM, Saxena S. World Health Organization's Global Action Plan on The Public Health Response to Dementia 2017-2025. Alzheimer's and Dementia. 2017; 13:P1450-1. https://doi.org/10.1016/j.jalz.2017.07.758

3. Alvarez JA, Emory E. Executive function and the frontal lobes: a meta-analytic review. Neuropsychol Rev. 2006; $16: 17-42$.

https://doi.org/10.1007/s11065-006-9002-x PMID: 16794878

4. Bancks MP, Allen NB, Dubey P, Launer $L$, Lloyd-Jones DM, Reis JP, Sidney S, Yano Y, Schreiner PJ. Cardiovascular health in young adulthood and structural brain MRI in midlife: the CARDIA study. Neurology. 2017; 89:680-6. https://doi.org/10.1212/WNL.0000000000004222 PMID:28724586

5. Barter JD, Foster TC. Aging in the brain: new roles of epigenetics in cognitive decline. Neuroscientist. 2018; 24:516-25. https://doi.org/10.1177/1073858418780971 PMID:29877135

6. Salthouse TA. Decomposing age correlations on neuropsychological and cognitive variables. J Int Neuropsychol Soc. 2009; 15:650-61. https://doi.org/10.1017/S1355617709990385 PMID:19570312

7. Gonzales MM, Wang CP, Quiben M, MacCarthy D, Seshadri S, Jacob M, Hazuda H. Joint trajectories of cognition and gait speed in Mexican American and European American older adults: the San Antonio longitudinal study of aging. Int J Geriatr Psychiatry. 2020; 35:897-906. 
https://doi.org/10.1002/gps.5310

PMID:32281153

8. Mungas D, Beckett L, Harvey D, Farias ST, Reed B, Carmichael O, Olichney J, Miller J, DeCarli C. Heterogeneity of cognitive trajectories in diverse older persons. Psychol Aging. 2010; 25:606-19. https://doi.org/10.1037/a0019502 PMID:20677882

9. Okonkwo OC, Cohen RA, Gunstad J, Tremont G, Alosco $M L$, Poppas A. Longitudinal trajectories of cognitive decline among older adults with cardiovascular disease. Cerebrovasc Dis. 2010; 30:362-73. https://doi.org/10.1159/000319564 PMID:20693791

10. Eavani $H$, Habes $M$, Satterthwaite TD, An $Y$, Hsieh MK, Honnorat N, Erus G, Doshi J, Ferrucci L, Beason-Held LL, Resnick SM, Davatzikos C. Heterogeneity of structural and functional imaging patterns of advanced brain aging revealed via machine learning methods. Neurobiol Aging. 2018; 71:41-50.

https://doi.org/10.1016/i.neurobiolaging.2018.06.013 PMID:30077821

11. Habes M, Grothe MJ, Tunc B, McMillan C, Wolk DA, Davatzikos C. Disentangling Heterogeneity in Alzheimer's Disease and Related Dementias Using Data-Driven Methods. Biol Psychiatry. 2020; 88:70-82. https://doi.org/10.1016/i.biopsych.2020.01.016 PMID:32201044

12. Elliott ML, Belsky DW, Knodt AR, Ireland D, Melzer TR, Poulton R, Ramrakha S, Caspi A, Moffitt TE, Hariri AR. Brain-age in midlife is associated with accelerated biological aging and cognitive decline in a longitudinal birth cohort. Mol Psychiatry. 2021; 26:3829-38. https://doi.org/10.1038/s41380-019-0626-7 PMID: $\underline{1822815}$

13. Wirth M, Villeneuve S, La Joie R, Marks SM, Jagust WJ. Gene-environment interactions: lifetime cognitive activity, APOE genotype, and $\beta$-amyloid burden. J Neurosci. 2014; 34:8612-7.

https://doi.org/10.1523/JNEUROSCI.4612-13.2014 PMID:24948815

14. Rogers J, Renoir T, Hannan AJ. Gene-environment interactions informing therapeutic approaches to cognitive and affective disorders. Neuropharmacology. 2019; 145:37-48.

https://doi.org/10.1016/j.neuropharm.2017.12.038 PMID:29277490

15. Chawla A, Cordner ZA, Boersma G, Moran TH. Cognitive impairment and gene expression alterations in a rodent model of binge eating disorder. Physiol Behav. 2017; 180:78-90. https://doi.org/10.1016/i.physbeh.2017.08.004 PMID:28821448

16. Pal S, Tyler JK. Epigenetics and aging. Sci Adv. 2016; 2:e1600584.

https://doi.org/10.1126/sciadv.1600584

PMID:27482540

17. Salameh Y, Bejaoui Y, El Hajj N. DNA Methylation Biomarkers in Aging and Age-Related Diseases. Front Genet. 2020; 11:171. https://doi.org/10.3389/fgene.2020.00171 PMID:32211026

18. Hannum G, Guinney J, Zhao L, Zhang L, Hughes G, Sadda S, Klotzle B, Bibikova M, Fan JB, Gao Y, Deconde $\mathrm{R}$, Chen M, Rajapakse I, et al. Genome-wide methylation profiles reveal quantitative views of human aging rates. Mol Cell. 2013; 49:359-67. https://doi.org/10.1016/j.molcel.2012.10.016 PMID:23177740

19. Horvath S. DNA methylation age of human tissues and cell types. Genome Biol. 2013; 14:R115. https://doi.org/10.1186/gb-2013-14-10-r115 PMID:24138928

20. Belsky DW, Moffitt TE, Cohen AA, Corcoran DL, Levine ME, Prinz JA, Schaefer J, Sugden K, Williams B, Poulton $\mathrm{R}$, Caspi A. Eleven telomere, epigenetic clock, and biomarker-composite quantifications of biological aging: do they measure the same thing? Am J Epidemiol. 2018; 187:1220-30.

PMID:29149257

21. Lu AT, Quach A, Wilson JG, Reiner AP, Aviv A, Raj K, Hou L, Baccarelli AA, Li Y, Stewart JD, Whitsel EA, Assimes TL, Ferrucci L, Horvath S. DNA methylation GrimAge strongly predicts lifespan and healthspan. Aging (Albany NY). 2019; 11:303-27. https://doi.org/10.18632/aging.101684 PMID:30669119

22. Horvath S, Raj K. DNA methylation-based biomarkers and the epigenetic clock theory of ageing. Nat Rev Genet. 2018; 19:371-84.

https://doi.org/10.1038/s41576-018-0004-3 PMID:29643443

23. Levine ME, Lu AT, Quach A, Chen BH, Assimes TL, Bandinelli S, Hou L, Baccarelli AA, Stewart JD, Li Y, Whitsel EA, Wilson JG, Reiner AP, et al. An epigenetic biomarker of aging for lifespan and healthspan. Aging (Albany NY). 2018; 10:573-91.

https://doi.org/10.18632/aging.101414 PMID:29676998

24. Farré P, Jones MJ, Meaney MJ, Emberly E, Turecki G, Kobor MS. Concordant and discordant DNA methylation signatures of aging in human blood and brain. Epigenetics Chromatin. 2015; 8:19.

https://doi.org/10.1186/s13072-015-0011-y PMID:25977707

25. Cevenini E, Invidia L, Lescai F, Salvioli S, Tieri P, Castellani G, Franceschi C. Human models of aging and 
longevity. Expert Opin Biol Ther. 2008; 8:1393-405. https://doi.org/10.1517/14712598.8.9.1393 PMID:18694357

26. Resnick SM, Pham DL, Kraut MA, Zonderman AB, Davatzikos $C$. Longitudinal magnetic resonance imaging studies of older adults: a shrinking brain. J Neurosci. 2003; 23:3295-301.

https://doi.org/10.1523/JNEUROSCI.23-08-03295.2003 PMID:12716936

27. Raz N, Lindenberger $U$, Rodrigue $K M$, Kennedy $K M$, Head D, Williamson A, Dahle C, Gerstorf D, Acker JD. Regional brain changes in aging healthy adults: general trends, individual differences and modifiers. Cereb Cortex. 2005; 15:1676-89.

https://doi.org/10.1093/cercor/bhi044

PMID:15703252

28. Habes M, Toledo JB, Resnick SM, Doshi J, Van der Auwera S, Erus G, Janowitz D, Hegenscheid K, Homuth G, Völzke H, Hoffmann W, Grabe HJ, Davatzikos C. Relationship between APOE Genotype and Structural MRI Measures throughout Adulthood in the Study of Health in Pomerania Population-Based Cohort. AJNR Am J Neuroradiol. 2016; 37:1636-42.

https://doi.org/10.3174/ajnr.A4805

PMID:27173368

29. Habes M, Erus G, Toledo JB, Zhang T, Bryan N, Launer L, Rosseel Y, Janowitz D, Doshi J, Van der Auwera S, von Sarnowski B, Hegenscheid K, Hosten N, et al. White matter hyperintensities and imaging patterns of brain ageing in the general population. Brain. 2016; 139:1164-79.

https://doi.org/10.1093/brain/aww008

PMID:26912649

30. Habes M, Janowitz D, Erus G, Toledo JB, Resnick SM, Doshi J, Van der Auwera S, Wittfeld K, Hegenscheid K, Hosten N, Biffar R, Homuth G, Völzke $H$, et al. Advanced brain aging: relationship with epidemiologic and genetic risk factors, and overlap with Alzheimer disease atrophy patterns. Transl Psychiatry. 2016; 6:e775.

https://doi.org/10.1038/tp.2016.39

PMID:27045845

31. Liu CC, Liu CC, Kanekiyo T, Xu H, Bu G. Apolipoprotein E and Alzheimer disease: risk, mechanisms and therapy. Nat Rev Neurol. 2013; 9:106-18.

https://doi.org/10.1038/nrneurol.2012.263

PMID:23296339

32. McCrory C, Fiorito G, Hernandez B, Polidoro S, O'Halloran AM, Hever A. NiCheallaigh C, Lu AT, Horvath S, Vineis P. Association of 4 epigenetic clocks with measures of functional health, cognition, and allcause mortality in The Irish Longitudinal Study on Ageing (TILDA). bioRxiv. 2020. https://doi.org/10.1101/2020.04.27.063164

33. Hillary RF, Stevenson AJ, Cox SR, McCartney DL, Harris SE, Seeboth A, Higham J, Sproul D, Taylor AM, Redmond P, Corley J, Pattie A, Hernández MDCV, et al. An epigenetic predictor of death captures multi-modal measures of brain health. Mol Psychiatry. 2021; 26:3806-16.

https://doi.org/10.1038/s41380-019-0616-9 PMID:31796892

34. Hughes TF, Ganguli M. Modifiable midlife risk factors for late-life cognitive impairment and dementia. Curr Psychiatry Rev. 2009; 5:73-92. https://doi.org/10.2174/157340009788167347 PMID:19946443

35. Maddock J, Castillo-Fernandez J, Wong A, Cooper R, Richards M, Ong KK, Ploubidis GB, Goodman A, Kuh D, Bell JT, Hardy R. DNA Methylation Age and Physical and Cognitive Aging. J Gerontol A Biol Sci Med Sci. 2020; 75:504-11.

https://doi.org/10.1093/gerona/glz246

PMID:31630156

36. Marioni RE, Shah S, McRae AF, Ritchie SJ, MunizTerrera G, Harris SE, Gibson J, Redmond P, Cox SR, Pattie A, Corley J, Taylor A, Murphy L, et al. The epigenetic clock is correlated with physical and cognitive fitness in the Lothian Birth Cohort 1936. Int J Epidemiol. 2015; 44:1388-96.

https://doi.org/10.1093/ije/dyu277

PMID:25617346

37. Zeki Al Hazzouri A, Stone KL, Haan MN, Yaffe K. Leptin, mild cognitive impairment, and dementia among elderly women. J Gerontol A Biol Sci Med Sci. 2013; 68:175-80.

https://doi.org/10.1093/gerona/gls155

PMID:22859388

38. Chai YL, Hilal S, Chong JP, Ng YX, Liew OW, Xu X, Ikram MK, Venketasubramanian N, Richards AM, Lai MK, Chen CP. Growth differentiation factor-15 and white matter hyperintensities in cognitive impairment and dementia. Medicine (Baltimore). 2016; 95:e4566. https://doi.org/10.1097/MD.0000000000004566 PMID:27537582

39. Lau WL, Fisher $M$, Greenia $D$, Floriolli $D$, Fletcher $E$, Singh B, Sajjadi SA, Corrada MM, Whittle C, Kawas C, Paganini-Hill A. Cystatin C, cognition, and brain MRI findings in 90+-year-olds. Neurobiol Aging. 2020; 93:78-84.

https://doi.org/10.1016/i.neurobiolaging.2020.04.022 PMID:32473464

40. Smith LK, He Y, Park JS, Bieri G, Snethlage CE, Lin K, Gontier G, Wabl R, Plambeck KE, Udeochu J, Wheatley $E G$, Bouchard J, Eggel $A$, et al. $\beta 2$-microglobulin is a 
systemic pro-aging factor that impairs cognitive function and neurogenesis. Nat Med. 2015; 21:932-7. https://doi.org/10.1038/nm.3898

PMID:26147761

41. Fernandez AP, Masa JS, Guedan MA, Futch HS, Martínez-Murillo R. Adrenomedullin Expression in Alzheimer's Brain. Curr Alzheimer Res. 2016; 13:428-38.

https://doi.org/10.2174/1567205013666160229112725

PMID:26923268

42. Oh J, Lee HJ, Song JH, Park SI, Kim H. Plasminogen activator inhibitor-1 as an early potential diagnostic marker for Alzheimer's disease. Exp Gerontol. 2014; 60:87-91.

https://doi.org/10.1016/i.exger.2014.10.004

PMID:25304332

43. Stomrud E, Björkqvist M, Janciauskiene S, Minthon L, Hansson O. Alterations of matrix metalloproteinases in the healthy elderly with increased risk of prodromal Alzheimer's disease. Alzheimers Res Ther. 2010; 2:20.

https://doi.org/10.1186/alzrt44

PMID:20576109

44. Sabia S, Elbaz A, Dugravot A, Head J, Shipley $M$, Hagger-Johnson $G$, Kivimaki $M$, Singh-Manoux $A$. Impact of smoking on cognitive decline in early old age: the Whitehall II cohort study. Arch Gen Psychiatry. 2012; 69:627-35.

https://doi.org/10.1001/archgenpsychiatry.2011.2016 PMID:22309970

45. Nakahachi $T$, Ishii $R$, Iwase $M$, Canuet $L$, Takahashi $H$, Kurimoto R, Ikezawa K, Azechi M, Sekiyama R, Honaga E, Uchiumi C, Iwakiri M, Motomura N, Takeda M. Frontal activity during the digit symbol substitution test determined by multichannel near-infrared spectroscopy. Neuropsychobiology. 2008; 57:151-8. https://doi.org/10.1159/000147467 PMID:18654084

46. Floden D, Vallesi A, Stuss DT. Task context and frontal lobe activation in the Stroop task. J Cogn Neurosci. 2011; 23:867-79.

https://doi.org/10.1162/jocn.2010.21492

PMID:20350183

47. Levine DA, Gross AL, Briceño EM, Tilton N, Giordani BJ, Sussman JB, Hayward RA, Burke JF, Hingtgen S, Elkind MS, Manly JJ, Gottesman RF, Gaskin DJ, et al. Sex Differences in Cognitive Decline Among US Adults. JAMA Netw Open. 2021; 4:e210169.

https://doi.org/10.1001/jamanetworkopen.2021.0169 PMID:33630089

48. Schiepers OJ, Harris SE, Gow AJ, Pattie A, Brett CE, Starr JM, Deary IJ. APOE E4 status predicts age-related cognitive decline in the ninth decade: longitudinal follow-up of the Lothian Birth Cohort 1921. Mol Psychiatry. 2012; 17:315-24.

https://doi.org/10.1038/mp.2010.137

PMID:21263443

49. Ianov L, Rani A, Beas BS, Kumar A, Foster TC. Transcription profile of aging and cognition-related genes in the medial prefrontal cortex. Front Aging Neurosci. 2016; 8:113.

https://doi.org/10.3389/fnagi.2016.00113

PMID:27242522

50. Morrison JH, Baxter MG. The ageing cortical synapse: hallmarks and implications for cognitive decline. Nat Rev Neurosci. 2012; 13:240-50.

https://doi.org/10.1038/nrn3200

PMID:22395804

51. Liao P, Ostrom QT, Stetson L, Barnholtz-Sloan JS. Models of epigenetic age capture patterns of DNA methylation in glioma associated with molecular subtype, survival, and recurrence. Neuro Oncol. 2018; 20:942-53.

https://doi.org/10.1093/neuonc/noy003 PMID:29432558

52. Shireby GL, Davies JP, Francis PT, Burrage J, Walker EM, Neilson GW, Dahir A, Thomas AJ, Love S, Smith RG, Lunnon K, Kumari M, Schalkwyk LC, et al. Recalibrating the epigenetic clock: implications for assessing biological age in the human cortex. Brain. 2020; 143:3763-75.

https://doi.org/10.1093/brain/awaa334 PMID:33300551

53. Funkhouser E, Wammack J, Roche C, Reis J, Sidney S, Schreiner P. Where are they now? Retention strategies over 25 years in the Coronary Artery Risk Development in Young Adults (CARDIA) Study. Contemp Clin Trials Commun. 2017; 9:64-70.

https://doi.org/10.1016/i.conctc.2017.12.003 PMID:29696226

54. Friedman GD, Cutter GR, Donahue RP, Hughes GH, Hulley SB, Jacobs DR Jr, Liu K, Savage PJ. CARDIA: study design, recruitment, and some characteristics of the examined subjects. J Clin Epidemiol. 1988; 41:1105-16. https://doi.org/10.1016/0895-4356(88)90080-7 PMID: 3204420

55. Launer LJ, Lewis CE, Schreiner PJ, Sidney S, Battapady $H$, Jacobs DR, Lim KO, D’Esposito M, Zhang Q, Reis J, Davatzikos C, Bryan RN. Vascular factors and multiple measures of early brain health: CARDIA brain MRI study. PLoS One. 2015; 10:e0122138.

https://doi.org/10.1371/journal.pone.0122138 PMID:25812012

56. Habes M, Pomponio R, Shou H, Doshi J, Mamourian E, Erus G, Nasrallah I, Launer L, Rashid T, Bilgel M, Fan Y, 
Toledo JB, Yaffe K, et al, and iSTAGING consortium, and the Preclinical $A D$ consortium, and the $A D N I$, and the CARDIA studies. The Brain Chart of Aging: machinelearning analytics reveals links between brain aging, white matter disease, amyloid burden, and cognition in the iSTAGING consortium of 10,216 harmonized MR scans. Alzheimers Dement. 2021; 17:89-102. https://doi.org/10.1002/alz.12178 PMID:32920988

57. Beier M, Hughes AJ, Williams MW, Gromisch ES. Brief and cost-effective tool for assessing verbal learning in multiple sclerosis: Comparison of the Rey Auditory Verbal Learning Test (RAVLT) to the California Verbal Learning Test - II (CVLT-II). J Neurol Sci. 2019; 400:104-9.

https://doi.org/10.1016/i.jns.2019.03.016

PMID:30913522

58. Jaeger J. Digit Symbol Substitution Test: The Case for Sensitivity Over Specificity in Neuropsychological Testing. J Clin Psychopharmacol. 2018; 38:513-9. https://doi.org/10.1097/JCP.0000000000000941 PMID:30124583

59. Kataoka S, Paidi M, Howard BV. Simplified isoelectric focusing/immunoblotting determination of apoprotein E phenotype. Clin Chem. 1994; 40:11-3. https://doi.org/10.1093/clinchem/40.1.11

PMID:8287516

60. Benjamini Y, Hochberg Y. Controlling the false discovery rate: a practical and powerful approach to multiple testing. 1995; 57:289-300.

https://doi.org/10.1111/i.2517-6161.1995.tb02031.x

61. Davies G, Armstrong N, Bis JC, Bressler J, Chouraki V, Giddaluru S, Hofer E, Ibrahim-Verbaas CA, Kirin M, Lahti J, van der Lee SJ, Le Hellard S, Liu T, et al, and Generation Scotland. Genetic contributions to variation in general cognitive function: a metaanalysis of genome-wide association studies in the CHARGE consortium ( $\mathrm{N}=53949)$. Mol Psychiatry. 2015; 20:183-92.

https://doi.org/10.1038/mp.2014.188

PMID:25644384

62. Robin X, Turck N, Hainard A, Tiberti N, Lisacek F, Sanchez JC, Müller M. pROC: an open-source package for $\mathrm{R}$ and $\mathrm{S}+$ to analyze and compare ROC curves. BMC Bioinformatics. 2011; 12:77.

https://doi.org/10.1186/1471-2105-12-77

PMID:21414208 


\section{SUPPLEMENTARY MATERIALS}

\section{Supplementary Methods}

\section{Illumina EPIC array methylation data quality control and preprocessing}

Infinium MethylationEPIC BeadChip raw data (IDAT files) were generated. The R package ENmix [1] was used for quality control with default parameter settings. Low-quality methylation measurements were identified by detection p-value $<10^{-6}$ or the number of beads $<3$ [1]. We excluded 6,209 CpGs with a detection rate $<95 \%$ and 87 samples with a percentage of low-quality methylation measurements $>5 \%$ or extremely low intensity of bisulfite conversion probes [1]. We further removed 95 samples that were extreme outliers, as defined by Tukey's method [i.e., $<25^{\text {th }}$ percentile $-3 *$ interquartile range (IQR) or $>75^{\text {th }}$ percentile $\left.+3 * \mathrm{IQR}\right]$ [2] and based on the average total intensity value [intensity of the unmethylated signal $(\mathrm{U})+$ intensity of the methylated signal $(\mathrm{M})]$ or $\beta$ value $[\mathrm{M} /(\mathrm{U}+\mathrm{M}+$ 100)] across $\mathrm{CpG}$ probes. The remaining samples were preprocessed using preprocessIllumina function in minfi package [3] before the estimations of epigenetic age.

\section{Spatial patterns of abnormality for recognition (SPARE) machine learning-based indices}

The SPARE-BA method relies on a multivariate pattern regression model to predict individualized brain age for each participant, similar to our previous work $[4,5]$. Support vector regression model (radial basis function kernel) was trained with the T1-MR scans using regional volumetric measures for structures. The training set included only cognitively normal subjects. The training set for SPARE-BA consisted of $(n=8,284)$ subjects from the iSTAGING consortium [6].

\section{Supplementary References}

1. Xu Z, Niu L, Li L, Taylor JA. ENmix: a novel background correction method for Illumina HumanMethylation450 BeadChip. Nucleic Acids Res. 2016; 44:e20. https://doi.org/10.1093/nar/gkv907 PMID:26384415
2. Tukey J. Exploratory Data Analysis: Pearson. 1977.

3. Aryee MJ, Jaffe AE, Corrada-Bravo H, Ladd-Acosta C, Feinberg AP, Hansen KD, Irizarry RA. Minfi: a flexible and comprehensive Bioconductor package for the analysis of Infinium DNA methylation microarrays. Bioinformatics. 2014; 30:1363-9. https://doi.org/10.1093/bioinformatics/btu049 PMID:24478339

4. Habes M, Erus G, Toledo JB, Zhang T, Bryan N, Launer $\sqcup$, Rosseel $\mathrm{Y}$, Janowitz D, Doshi J, Van der Auwera S, von Sarnowski B, Hegenscheid K, Hosten N, et al. White matter hyperintensities and imaging patterns of brain ageing in the general population. Brain. 2016; 139:1164-79.

https://doi.org/10.1093/brain/aww008 PMID:26912649

5. Eavani H, Habes M, Satterthwaite TD, An Y, Hsieh MK, Honnorat N, Erus G, Doshi J, Ferrucci L, Beason-Held LL, Resnick SM, Davatzikos C. Heterogeneity of structural and functional imaging patterns of advanced brain aging revealed via machine learning methods. Neurobiol Aging. 2018; 71:41-50. https://doi.org/10.1016/i.neurobiolaging.2018.06.013 PMID:30077821

6. Habes M, Pomponio R, Shou H, Doshi J, Mamourian E, Erus $G$, Nasrallah I, Launer $L$, Rashid T, Bilgel M, Fan $Y$, Toledo JB, Yaffe $K$, et al. The Brain Chart of Aging: Machine-learning analytics reveals links between brain aging, white matter disease, amyloid burden, and cognition in the iSTAGING consortium of 10,216 harmonized MR scans. Alzheimers Dement. 2021; 17:89-102.

https://doi.org/10.1002/alz.12178

PMID:32920988 


\section{Supplementary Figures}

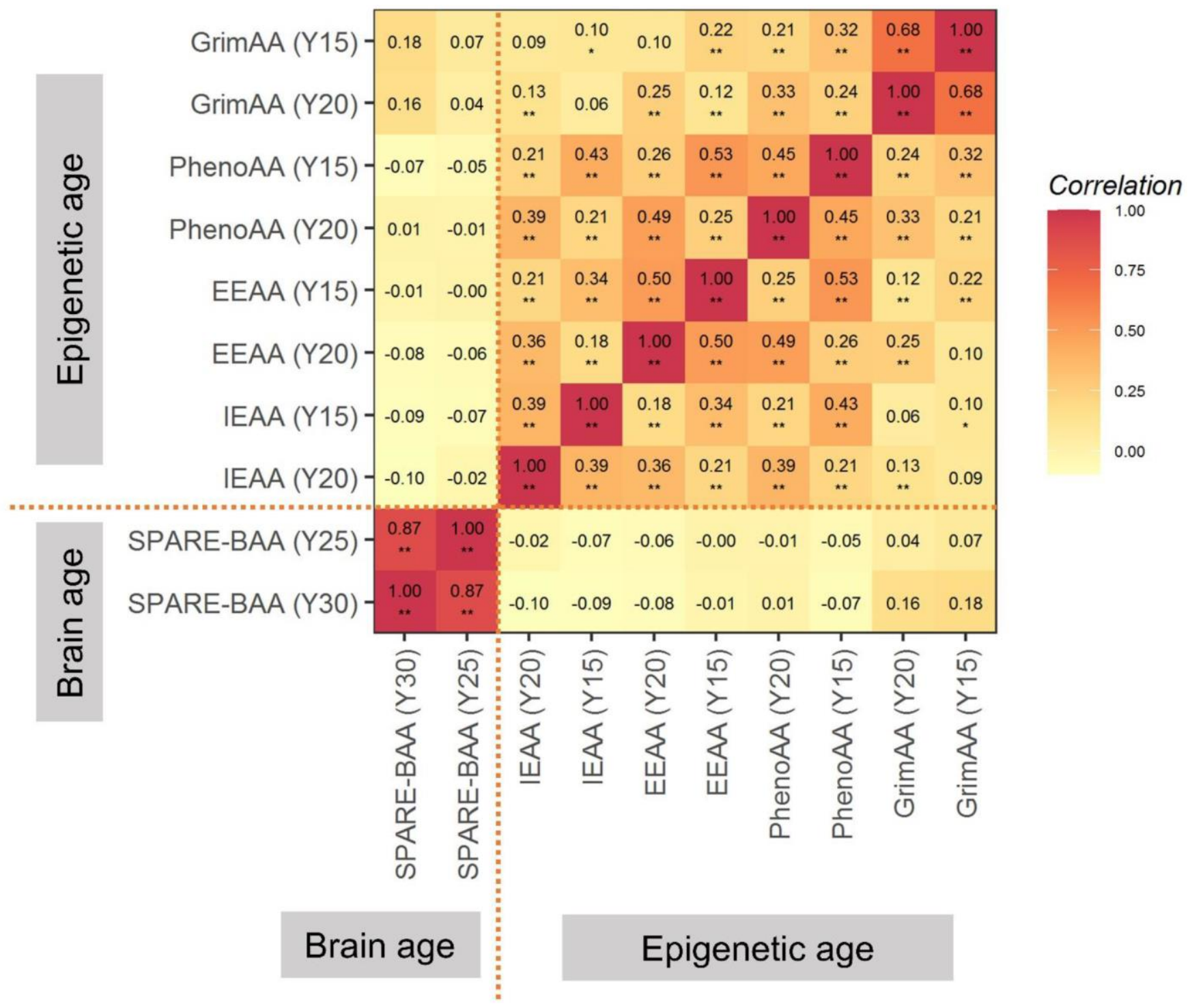

Supplementary Figure 1. Pairwise correlations of epigenetic aging markers and brain aging markers. Multiple comparisons were adjusted using the Holm-Bonferroni method. *: adjusted- $\mathrm{p}<0.05 ;{ }^{* *}$ : adjusted- $\mathrm{p}<0.01$. 

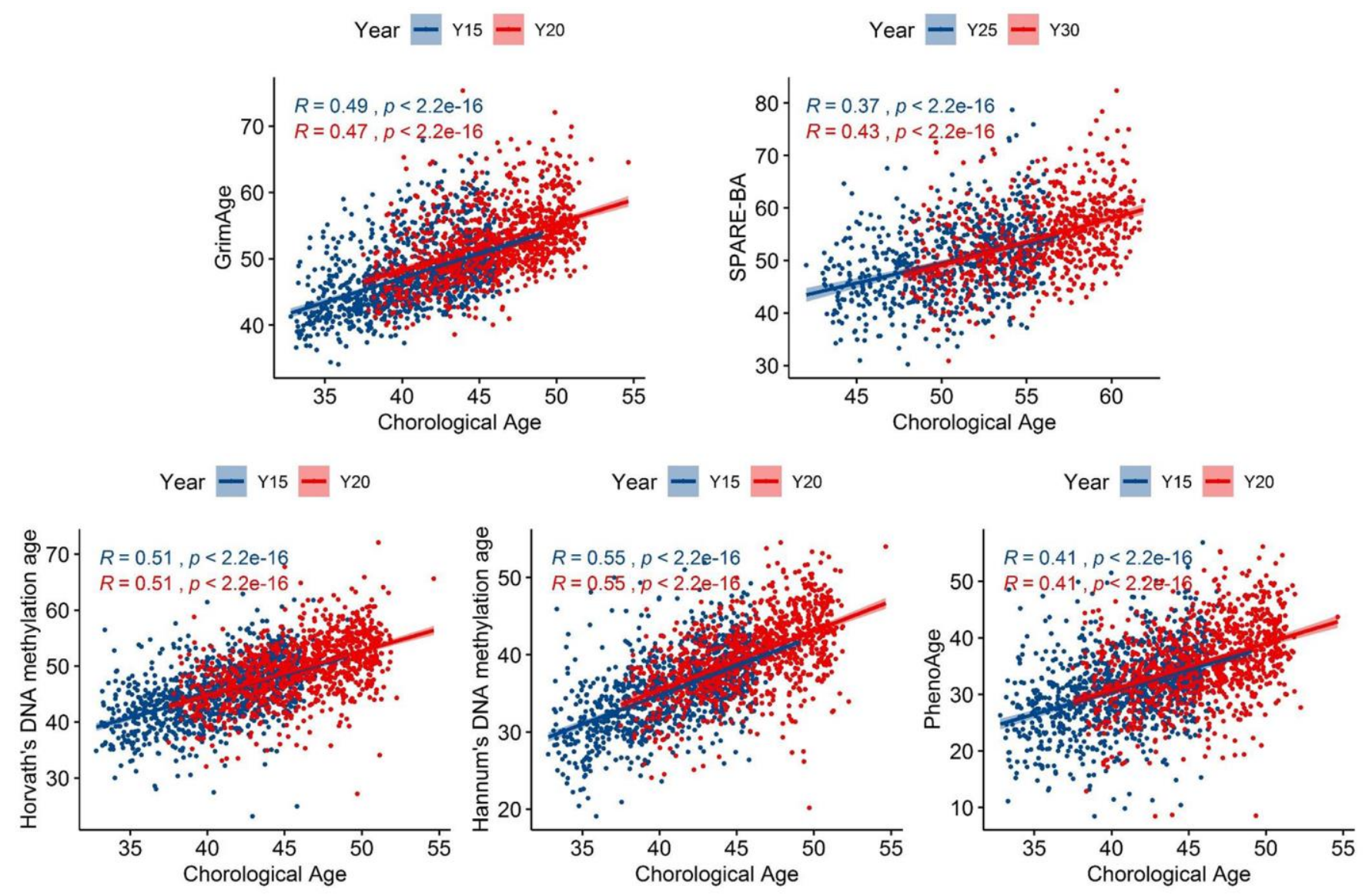

Supplementary Figure 2. Correlations between epigenetic age, brain age, and chronological age.

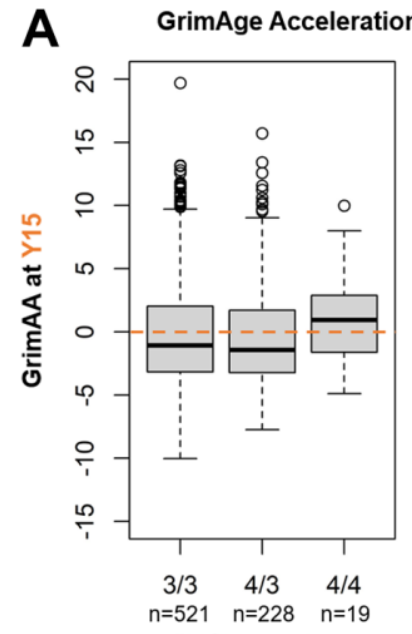

APOE genotypes

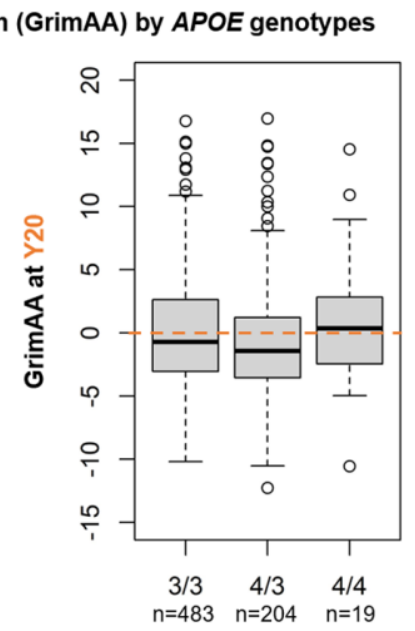

APOE genotypes

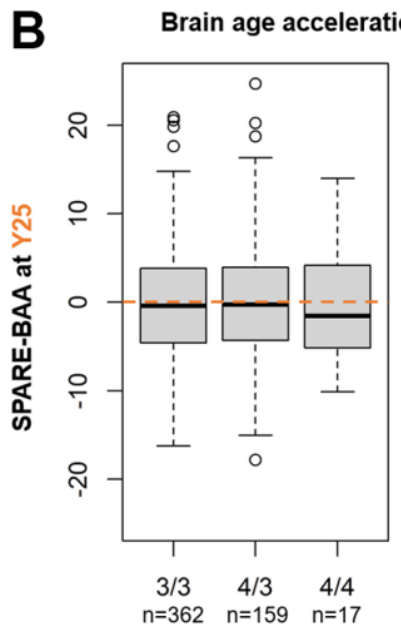

APOE genotypes

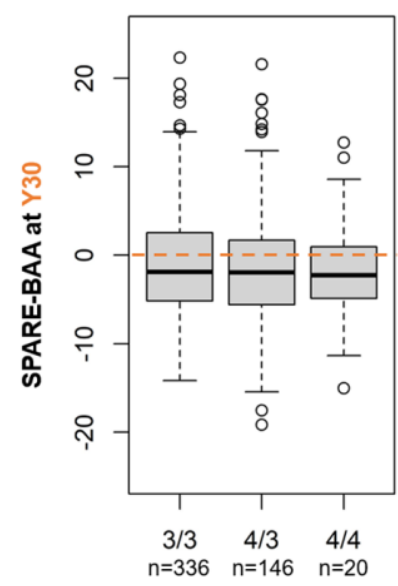

APOE genotypes

Supplementary Figure 3. GrimAge acceleration and SPARE brain age acceleration by APOE genotypes. (A) Y15 and Y20 GrimAA by APOE genotypes. (B) Y25 and Y30 SPARE-BAA by APOE genotypes. GrimAA was greater than 0 among those who were homozygous carrier (APOE 4/4) and higher than the non-carrier (APOE $3 / 3$ ) and heterozygous (APOE $4 / 3)$ but not statistically significant $(p<0.05)$. SPARE-BAA was roughly equal across three genotype groups. 

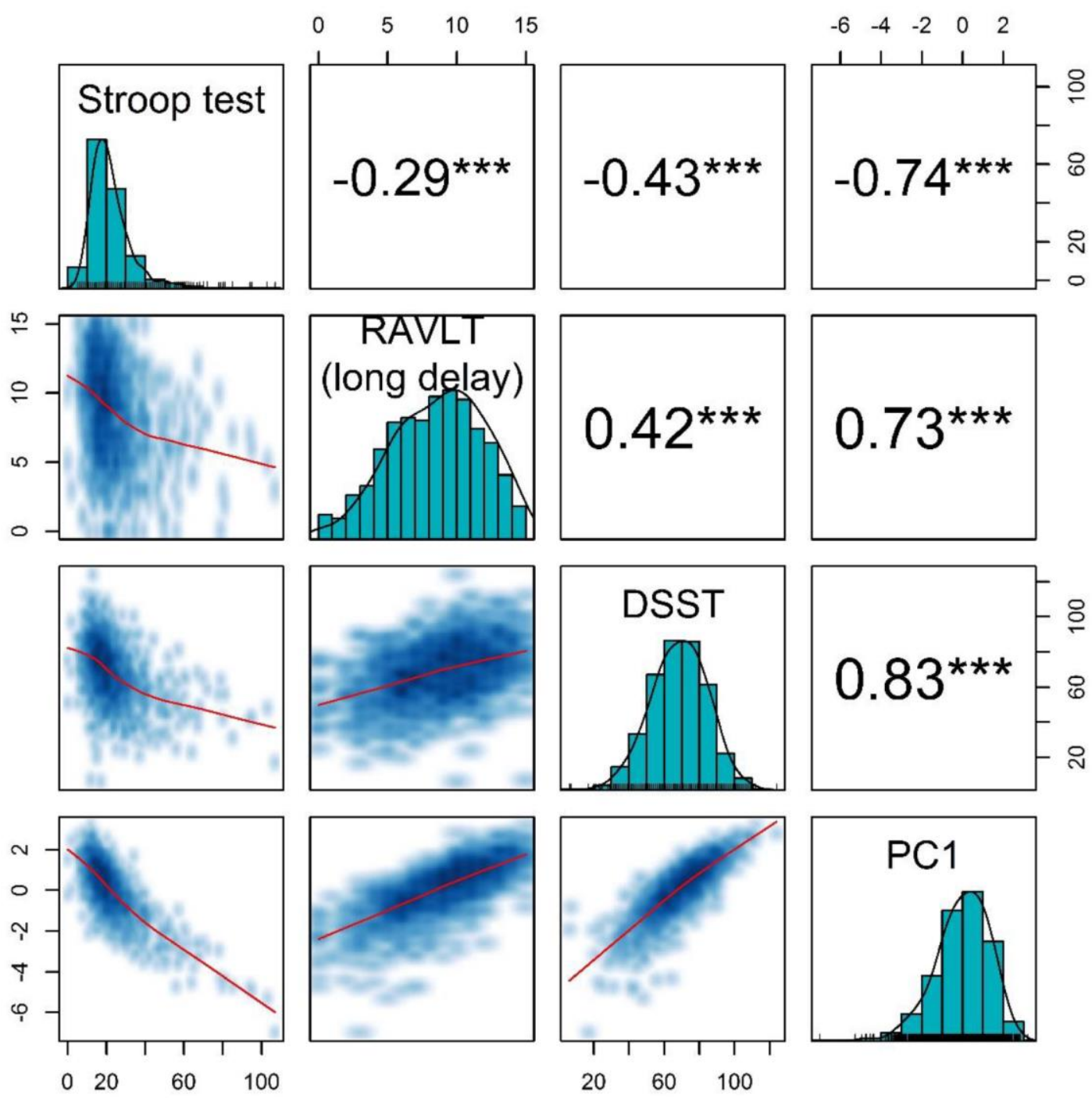

Supplementary Figure 4. Correlations between cognitive testing and the first principal component (PC1) across the tests. The PC1 was negatively associated with Stroop test and positively correlated with RAVLT long delay free recall and DSST. Higher PC1 levels indicate better cognitive performance. The star symbols beside the Pearson's correlation indicate the significance of the correlation test. 


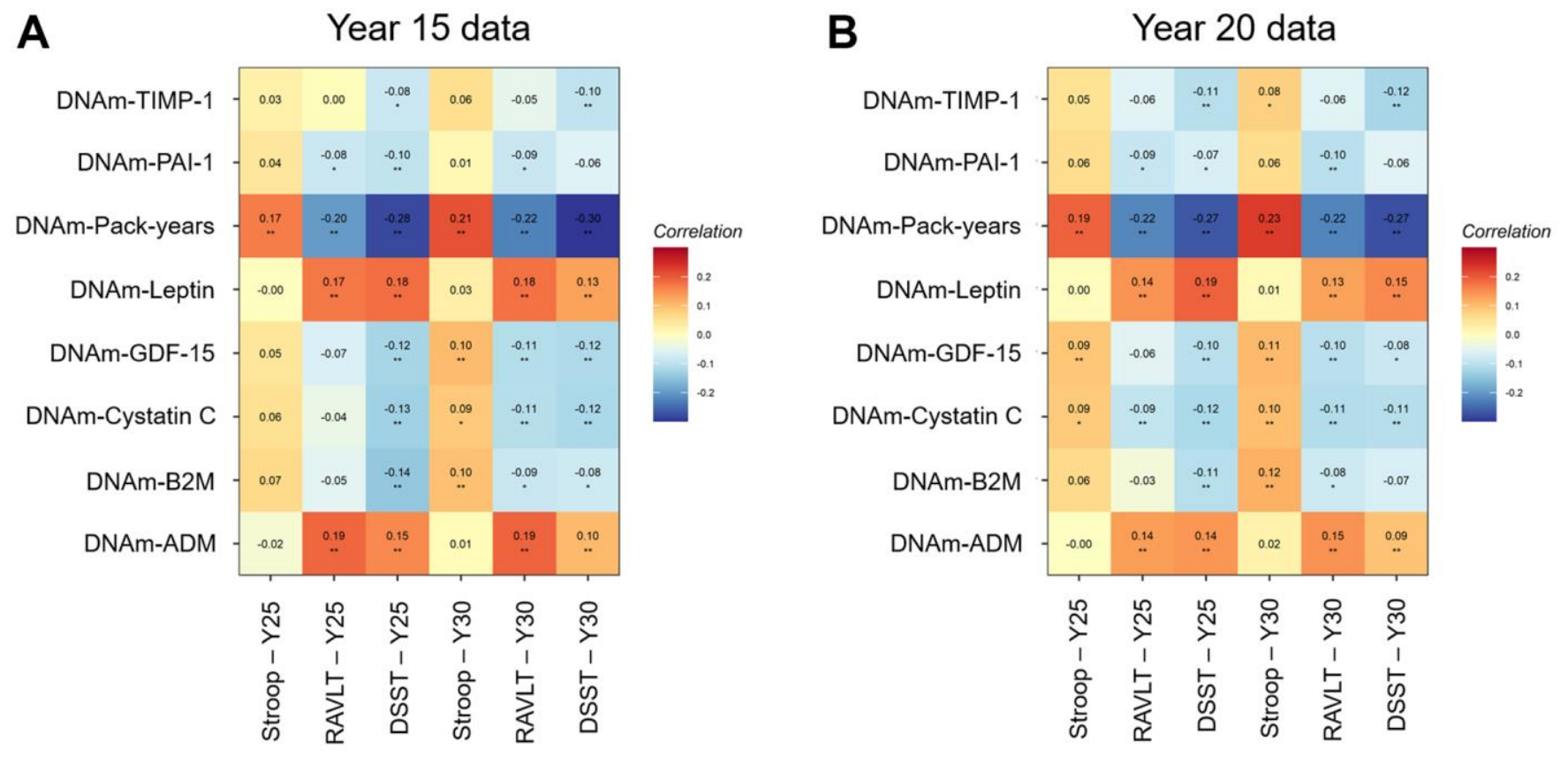

Supplementary Figure 5. Correlation heatmaps between DNA methylation surrogates components of GrimAge and cognitive testings. (A) GrimAge methylation components were estimated using Y15 methylation data. (B) GrimAge methylation components were estimated using Y20 methylation data. All seven DNA methylation surrogates of plasma protein and pack years of GrimAge were significantly correlated with at least one type of the 3 cognitive testings. In general, Y30 cognition measures resulted in higher correlation compared to Y25 cognition measures. DNAm: DNA methylation; ADM: adrenomedullin; B2M: $\beta 2$-microglobulin; GDF-15: growth differentiation factor-15; PAI-1: plasminogen activator inhibitor 1; TIMP-1: tissue inhibitor metalloproteinase-1. 


\section{Supplementary Tables}

Supplementary Table 1. Associations between IEAA, EEAA, and PhenoAA vs. cognitive function.

\begin{tabular}{|c|c|c|c|c|c|c|c|c|c|c|c|c|}
\hline \multirow[b]{2}{*}{ Analysis type } & \multirow[b]{2}{*}{$\begin{array}{c}\text { Epigenetic } \\
\text { aging marker }\end{array}$} & \multicolumn{4}{|c|}{ Stroop test } & \multicolumn{4}{|c|}{ RAVLT-long delay free recall } & \multicolumn{3}{|c|}{ DSST } \\
\hline & & $\begin{array}{c}\text { Coefficient } \\
(95 \% \text { CI })\end{array}$ & $\mathbf{p}$ & dj.p ${ }^{1}$ & n & $\begin{array}{c}\text { Coefficient } \\
(95 \% \text { CI })\end{array}$ & $\mathbf{p}$ & Adj.p ${ }^{1}$ & $1 \mathrm{n}$ & $\begin{array}{c}\text { Coefficient } \\
(95 \% \text { CI })\end{array}$ & $\mathbf{p}$ & Adj.p ${ }^{1} \mathrm{n}$ \\
\hline \multirow{3}{*}{$\begin{array}{l}\text { 5-year prospective } \\
\text { analysis }{ }^{2} \\
\text { (Y20 epigenetic aging } \\
\text { vs. Y25 Cognition) }\end{array}$} & IEAA & $\begin{array}{c}0.027 \\
(-0.112,0.166)\end{array}$ & 0.701 & 0.943 & 920 & $\begin{array}{c}0.001 \\
(-0.038,0.041)\end{array}$ & 0.943 & 0.943 & 927 & $\begin{array}{c}0.066 \\
(-0.126,0.259)\end{array}$ & 0.4 & 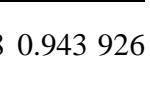 \\
\hline & EAA & $\begin{array}{c}0.060 \\
(-0.067,0.186)\end{array}$ & 0.357 & 0.453 & 923 & $\begin{array}{c}-0.014 \\
(-0.049,0.022)\end{array}$ & 0.453 & 0.453 & 930 & $\begin{array}{c}-0.140 \\
(-0.315,0.034)\end{array}$ & 0.1 & \\
\hline & & $\begin{array}{c}-0.013 \\
(-0.115,0.088)\end{array}$ & 0.795 & & 924 & $\begin{array}{c}-0.018 \\
(-0.046,0.011)\end{array}$ & 0.220 & 0.330 & 931 & $\begin{array}{c}-0.157 \\
(-0.297,-0.018)\end{array}$ & 0.027 & \\
\hline \multirow{3}{*}{$\begin{array}{l}\text { 15-year prospective } \\
\text { analysis }{ }^{2} \\
\text { (Y15 epigenetic aging } \\
\text { vs. Y30 Cognition) }\end{array}$} & IEA & $\begin{array}{c}0.031 \\
(-0.128,0.191)\end{array}$ & 0.700 & 0.700 & 888 & $\begin{array}{c}0.025 \\
(-0.017,0.067)\end{array}$ & 0.248 & 0.470 & 903 & $\begin{array}{c}-0.107 \\
(-0.314,0.101)\end{array}$ & 0.313 & 0.4 \\
\hline & EEAA & $\begin{array}{c}0.006 \\
(-0.129,0.142)\end{array}$ & 0.926 & 0.926 & 890 & $\begin{array}{c}0.005 \\
(-0.031,0.041)\end{array}$ & 0.795 & 0.926 & 905 & $\begin{array}{c}-0.094 \\
(-0.269,0.082)\end{array}$ & 0.294 & 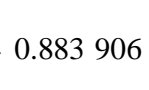 \\
\hline & PhenoAA & $\begin{array}{c}0.062 \\
(-0.054,0.178)\end{array}$ & 0.298 & 0.437 & 890 & $\begin{array}{c}-0.012 \\
(-0.043,0.019)\end{array}$ & 0.437 & 0.437 & 905 & $\begin{array}{c}-0.087 \\
(-0.237,0.062) \\
\end{array}$ & 0.2 & 0.4 \\
\hline
\end{tabular}

${ }^{1} \mathrm{BH}-\mathrm{FDR}$ adjustment was applied to account for multiple testing for each aging marker across all the cognitive function tests. ${ }^{2}$ Multiple linear regression models adjusting for age, sex, race, study fields, and education.

Supplementary Table 2. Associations between a five-year change of epigenetic age (Y15-Y20) and brain age (Y25-Y30) vs. cognitive function at Y30.

\begin{tabular}{|c|c|c|c|c|c|c|c|c|c|}
\hline \multirow{2}{*}{ Aging marker } & \multicolumn{3}{|c|}{$\begin{array}{l}\text { Stroop test } \\
\quad(\text { Y30) }\end{array}$} & \multicolumn{3}{|c|}{$\begin{array}{l}\text { RAVLT-long delay free recall } \\
\text { (Y30) }\end{array}$} & \multicolumn{3}{|c|}{$\begin{array}{l}\text { DSST } \\
(\text { Y30) } \\
\end{array}$} \\
\hline & $\begin{array}{l}\text { Coefficient } \\
(95 \% \text { CI })\end{array}$ & $\mathbf{p}$ & ${\operatorname{Adj} . p^{1} n}$ & $\begin{array}{l}\text { Coefficient } \\
(95 \% \text { CI })\end{array}$ & $\mathbf{p}$ & Adj.p ${ }^{1}$ n & $\begin{array}{l}\text { Coefficient } \\
(95 \% \text { CI })\end{array}$ & $\mathbf{p}$ & Adj.p ${ }^{1} n$ \\
\hline $\begin{array}{l}\text { Horvath's epigenetic age } \\
\text { (5-year change) }\end{array}$ & $\begin{array}{c}0.097 \\
(-0.041,0.235)\end{array}$ & 0.169 & 0.169757 & $\begin{array}{c}0.028 \\
(-0.011,0.066)\end{array}$ & 0.161 & 0.169768 & $\begin{array}{c}0.162 \\
(-0.028,0.352)\end{array}$ & 0.094 & 0.169770 \\
\hline $\begin{array}{l}\text { Hannum's epigenetic age } \\
\text { (5-year change) }\end{array}$ & $\begin{array}{c}0.098 \\
(-0.071,0.266)\end{array}$ & 0.255 & 0.395758 & $\begin{array}{c}0.026 \\
(-0.021,0.073)\end{array}$ & 0.273 & 0.395769 & $\begin{array}{c}0.100 \\
(-0.130,0.329)\end{array}$ & 0.395 & 0.395771 \\
\hline $\begin{array}{l}\text { PhenoAge } \\
\text { (5-year change) }\end{array}$ & $\begin{array}{c}0.008 \\
(-0.100,0.116)\end{array}$ & 0.887 & 0.887759 & $\begin{array}{c}0.003 \\
(-0.027,0.033)\end{array}$ & 0.832 & 0.887770 & $\begin{array}{c}-0.060 \\
(-0.208,0.088)\end{array}$ & 0.429 & 0.887772 \\
\hline $\begin{array}{l}\text { GrimAge } \\
\text { (5-year change) }\end{array}$ & $\begin{array}{c}0.106 \\
(-0.084,0.296)\end{array}$ & 0.276 & 0.423759 & $\begin{array}{c}0.006 \\
(-0.047,0.058)\end{array}$ & 0.836 & 0.8367 & $\begin{array}{c}0.144 \\
(-0.118,0.406)\end{array}$ & 0.282 & 0.423772 \\
\hline $\begin{array}{l}\text { SPARE-BA } \\
(5 \text {-year change) }\end{array}$ & $\begin{array}{c}0.478 \\
(0.186,0.770) \\
\end{array}$ & 0.001 & $\mathbf{0 . 0 0 4} 469$ & $\begin{array}{c}-0.017 \\
(-0.101,0.068) \\
\end{array}$ & 0.701 & 0.701474 & $\begin{array}{c}-0.454 \\
(-0.843,-0.066) \\
\end{array}$ & 0.022 & $\mathbf{0 . 0 3 3} 475$ \\
\hline
\end{tabular}

Note: Since the changes of the aging marker over time were evaluated, the age estimates rather than the age acceleration were used.

${ }^{1} \mathrm{BH}-\mathrm{FDR}$ adjustment was applied to account for multiple testing for each aging marker across all the cognitive function tests. ${ }^{2}$ Multiple linear regression models adjusting for age, sex, race, study fields, and education. 
Supplementary Table 3. Associations between GrimAge acceleration and SPARE-brain age acceleration vs. cognitive function by sex.

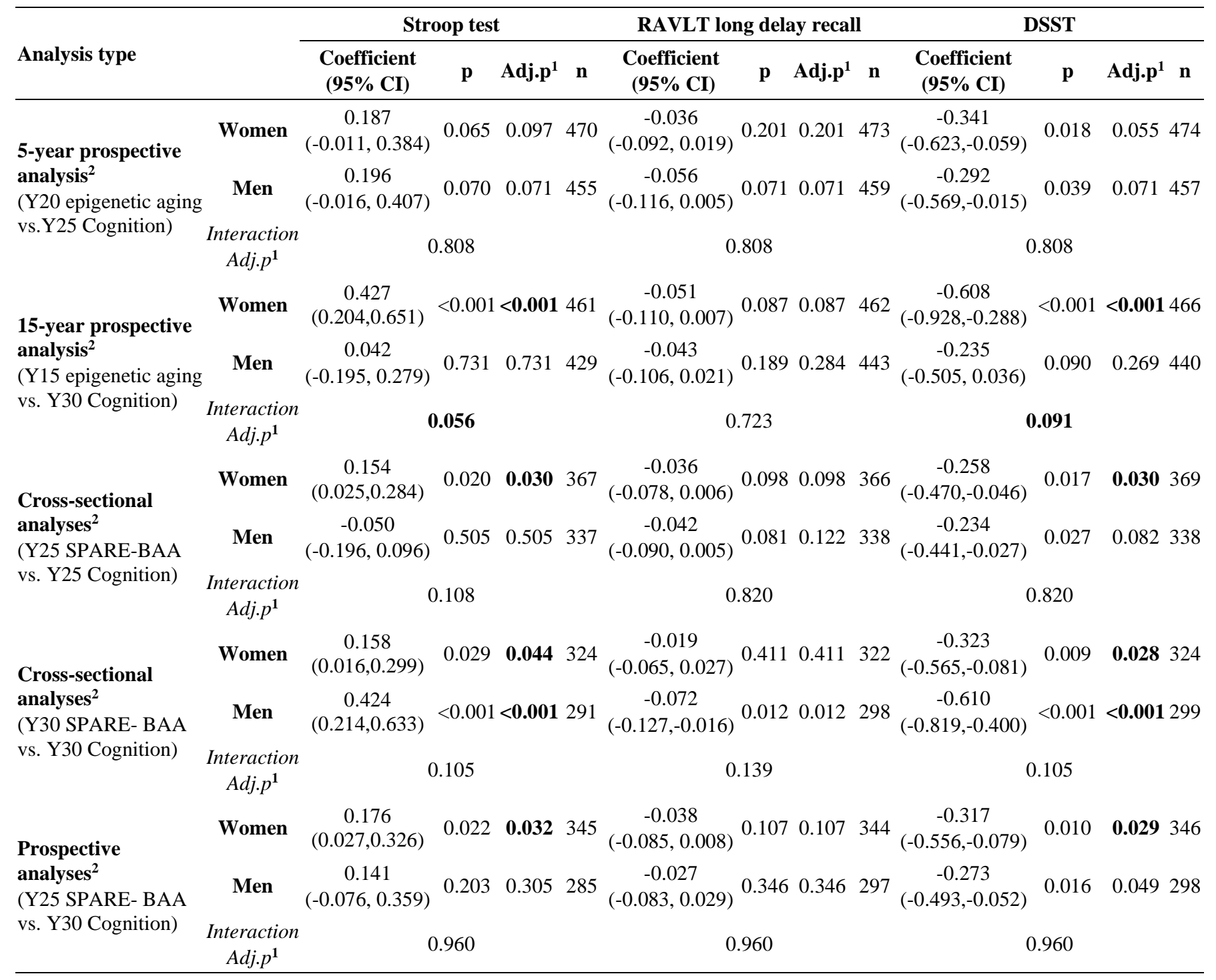

${ }^{1} \mathrm{BH}-\mathrm{FDR}$ adjustment was applied to account for multiple testing for each aging marker across all the cognitive function tests.

${ }^{2}$ Multiple linear regression models adjusting for age, race, study fields, and education. 
Supplementary Table 4. Associations between GrimAge acceleration and SPARE-brain age acceleration vs. cognitive function by APOE genotype (APOE 3/3 non-carrier vs. APOE 4/3 or 4/4 carrier).

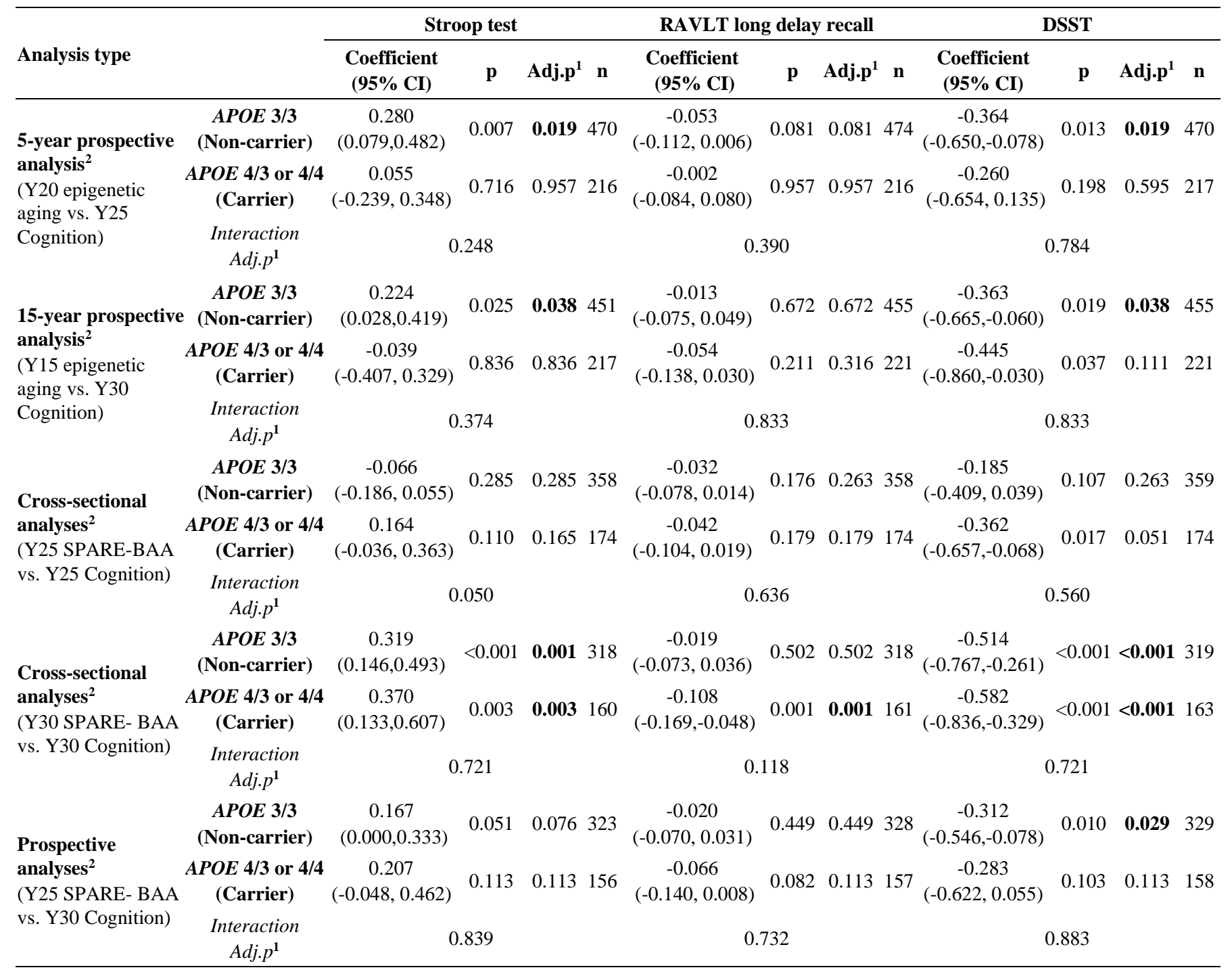

${ }^{1} \mathrm{BH}-\mathrm{FDR}$ adjustment was applied to account for multiple testing for each aging marker across all the cognitive function tests. ${ }^{2}$ Multiple linear regression models adjusting for age, sex, race, study fields, and education. 